\title{
ANÁLISE ESTRUTURAL DA REGIÃO DE ABADIÂNIA (GO)
}

\author{
ADELIR JOSÉ STRIEER*
}

\begin{abstract}
STRUCTURAL ANALYSIS IN THE ABADIÂNIA REGION (GO). This paper presents the results of a detailed structural analysis carried out in the Abadiânia region in the state of Goiás, which allowed the recognition of five deformational surfaces correlated with thrust processes. The paper was divided into five parts, describing the deformational fabrics, analysing the last deformational phase and its relationship with the proceeding ones, discussing the regional significance of the recognized structure, and showing the structural relationship between serpentinite bodies and their country rocks. The structural analysis was performed by the subdivision of the area into homogeneous domains with regard to $K_{1}$ and $K_{2}$ deformational surfaces. The second part of the paper deals with the analysis of the structural data of each delimitated domain in order to determine the nature of the $K_{1}$ and $K_{2}$ surfaces. These surfaces were defined as conjugated directional shear surfaces developed during the $\mathrm{D}_{3}$ deformational phase. A more global analysis of the deformation was proceeded in the third part, which allowed to determine the original position of the $\mathrm{S}_{2}$ surface $\left(200-25 \mathrm{NW}\right.$ ), indicate a small initial angular relationship between $S_{1}$ and $\mathrm{S}_{2}$ and suggest a kinematic relationship between the development of each deformational surface. In the fourth part, is presented a discussion aiming to correlate the observed regional structures with the common structures described in convergent plate margins. Itw as, thus, possible to interpret the $K_{1}$ directional surfaces as lateral ramps of a thrust sheet, which introduced a wrench-type component that possibly generated a regional sheath geometry on a large $\mathrm{F}_{2}$ nappe. In this kind of situation, the actual geomorphological expression of the Pirineus Inflexion can be treated as the result of differential movement of the thrust sheet. Finally, it was concluded that the serpentinite bodies underwent all deformational events, since they exhibt all identified deformational surfaces and their internal structure is similar to that of the country rocks.
\end{abstract}

Keywords: Deformation, structural analysis, structural domains, structure of Pirineus inflexion, directional structures, regional kink.

\begin{abstract}
RESUMO Este artigo apresenta os resultados de uma detalhada análise estrutural que foi realizada na região de Abadiânia (Estado de Goiás) e que permitiu o reconhecimento de cinco superfícies deformacionais correlacionadas com processos de cavalgamento. O artigo foi dividido em cinco partes: descreve as petrotramas deformacionais, analisa a última fase deformacional e a sua relação com as fases precedentes, discute o significado regional da estrutura reconhecida e apresenta as relações estruturais entre os corpos de serpentinito e as suas encaixantes. A análise estrutural foi realizada pela subdivisão da área em domínios homogêneos com relação às superfícies KI e $\mathrm{K}_{2}$. A segunda parte do artigo trata da análise dos dados estruturais de cada domínio delimitado para investigar a natureza das superficies $\mathrm{K}_{1}$ e $\mathrm{K}_{2}$. Estas superfícies foram, então, definidas como superfícies conjugadas de cisalhamento direcional desenvolvidas durante a fase $\mathrm{D}_{3}$. Uma análise mais global da deformacão foi realizada na terceira parte, o que permitiu determinar a posição original da superficie $S_{2}(200-25 \mathrm{NW})$, indicar uma pequena angularidade inicial entre $S_{1}$ e $S_{2}$ e sugerir uma relação cinemática entre o desenvolvimento de cada superficie deformacional. Na quarta parte, é realizada uma ampla discussão no sentido de correlacionar a estrutura regional observada com as estruturas normalmente descritas em zonas de convergência. A partir disto, foi possível indicar as superfícies direcionais $\mathrm{K}_{1}$ como rampas laterais de uma lâmina de cavalgamento. Estas superfícies introduziram uma componente tipo wrench que possivelmente deu origem a uma geometria "em bainha" para a grande nappe $\mathrm{F}_{2}$. Nesse caso, a atual expressão geomorfològica da Inflexão dos Pirineus pode ser vista como o resultado do movimento diferencial da lâmina de cavalgamento. Por fim, foi concluído que os corpos de serpentinito foram envolvidos em todas as fases deformacionais, pois possuem todas as superfícies deformacionais identificadas, e a sua estrutura interna é semelhante àquela das rochas encaixantes.
\end{abstract}

Palavras-chaves: Deformação, análise estrutural, domínios estruturais, estruturação da inflexão dos Pirineus, zonas de cavalgamento, estruturas direcionais, kinks regionais.

INTRODUÇÃO Embora alguns trabalhos (Drake Jr. 1980, Araújo $F^{\mathrm{o}}$ 1981, Simões \& Fuck 1984, Araújo $\mathrm{F}^{\mathrm{o}}$ \& Leonardos 1986, Heilbron et al. 1987) tenham se preocupado com as estruturas deformacionais impressas nos metassedimentos Araxá pela categorização e pela hierarquização das fases deformacionais, nenhum deles apresenta uma completa análise estrutural baseada na compartimentação de domínios relativamente homogêneos com relação a cada uma das fases deformacionais identificadas. Portanto, o objetivo deste trabalho é apresentar os resultados de um. mapeamento estrutural e litológico realizado na região de Abadiânia (GO), para o qual foram utilizados vários procedimentos de análise estrutural. Uma discussão mais extensa da compartimentação, da estrutura interna de cada segmento e dos vários detalhes que cercam a análise estruturai procedida é apresentada por Strieder (1989). A região de Abadiânia (Fig. 1) está situada na entidade geotectônica genericamente denominada de Província Estrutural do Tocantins (Cordani \& Brito Neves 1982), e é composta essencialmente pelos metassedimentos Araxá; estes metassedimentos contêm abundantes corpos de rochas máficas e ultramáficas, de mármores e de "material" quartzo-feldspático e, por estas características, são interpretados como uma melange ofiolítica (Drake Jr. 1980). Posteriormente, Strieder \& Nilson (subm) analisam profundamente o significado desta interpretação frente a incorporação de novos dados e concluem que esta associação petrotectônica é um depósito de calha de subducção envolvido em processos de cavalgamento.

Neste trabalho, as medidas de atitude dos elementos estruturais são fornecidas na notação azimutal, de acordo com uma pequena modificação da "regra da mão direita", utilizada pelos geólogos ingleses (Barnes 1981). Por essa notação, a direção azimutal dos elementos planares é sempre referida ao 


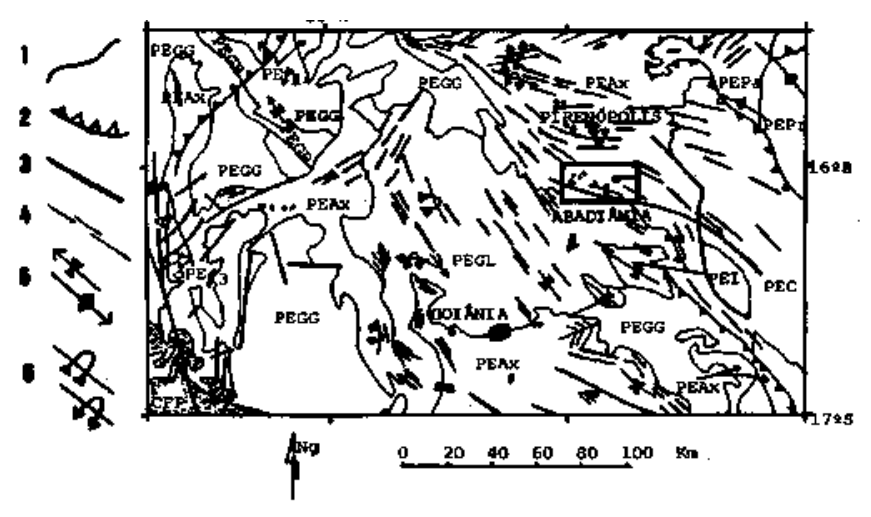

Figura I - Localizaçấo da regiāo de Abadiania (GO) no Mapa Geologico Regional. Este mapa é una reproduç̄o parcial daquele fornecido por Marini et al. (1979). Legenda estratigráfica: (CFP) Coberturas Fanerozóicas Plataformais; (PEPr) Formação Paraopeba; (PEI) Formaçäo Ibia; ( $P E_{\gamma_{3}}$ ) Graritos tipo Estrela do Sul; (PEPa) Formaçāo Paranod; (PEC) Grupo Canastra; (PEAx) Grupo Araxd; ( O ) Corpos de serpentinito encaixados nos metassedimentos do Grupo Araxd; (PE ${ }_{\gamma_{1}}$ ) Granitos tipo Rubiataba; (PEGL) Complexo Granulfico; (PEGB) Seqüéncias Greenstone Belts; (PEGG) Complexo Grantito-gnatssico. Legenda de estruturas: 1. Contatos litoWgicos; 2. Falhas de empurrâo; 3. Fathas indiscriminadas; 4. Linhas estrutuais indiscriminadas; 5. Sinclinal $e$ anticlinal com cainento; 6. Sinclinal e anticlinal invertidas

Figure I - Locelization of the Abedilinia (GO) region in the Regional Geologic Map. This map is a partial roproduction from that showed by Marini et al. (1979). Stratigraphic kegend: (CFP) Phanerozoic Plataformal Covers; (PEPr) Paraopeba Formation; (PEI) Ibid Formation; (PE $y_{3}$ ) Estrela do Sul, type granites; (PEPa) Partinot Formation; (PEC) Canastra Group; (PEAx) Araxf Group; ( 0 ) Serpentinite bodies emplaced in Arax 4 Group metusediments; $\left(\mathrm{PE}_{\gamma_{1}}\right)$ Rubintaba-type granites; (PEGL) Granulitic Complex; (PEGB) Greenstone Belss Sequences; (PEGG) Granite-gneissic Complex. Structures' legend: 1. Lithologic contact; 2. Thrust faults; 3. Uncharacterized faltes; 4. Uncharacterized structural lineaments; 5. Dipping synclinal or anticlinal; 6. Overtumed synelinal or anticlinal

indicador da mão esquerda, de modo que o mergulho seja sempre ortogonalmente indicado pelo polegar esquerdo; para facilitar a familiarização com a notação, usa-se os quadrantes de rumo para indicar o sentido do mergulho. Os elementos lineares, por sua vez, têm sua medida de caimento referida também à direção azimutal.

As notações $S_{1}$ e $S_{2}, D_{1} D_{2}, B_{1}{ }^{2}$ e $\mathbf{B}_{1}{ }^{2}$ são tomadas a partir de Turner \& Weiss (1963) e indicam, respectiva e cronologicamente, as superfícies geradas na primeira e na segunda fases deformacionais, os eixos das dobras resultantes da superposição destas fases deformacionais e o eixo geométrico de dobra obtido por construção gráfica. A terceira fase de deformação $\left(\mathrm{D}_{3}\right)$, por possuir duas superfícies conjugadas, tem a notação clássica de superfícies deformacionais modificada para $\mathrm{K}_{1} \mathrm{e}$ $\mathrm{K}_{2}$; assim, as lineações geradas pela superposição dessas superfícies são designadas ou pela notação $\mathbf{B}^{\mathbf{k n}}{ }_{\mathbf{s}}$, na qual $\mathbf{n}$ representa a superfície de $\mathrm{D}_{3}$ que está superposta à $\mathbf{s}\left(\mathrm{S}_{1}\right.$ ou $\left.\mathrm{S}_{2}\right)$, ou pela notação $\mathbf{B}_{\mathbf{k}}$ que designa os eixos de kink e a superposição das duas superfícies conjugadas. As direções de cisalhamento, obtidas a partir da análise estrutural, são designadas pela notação $\mathbf{a}_{\mathbf{k n}}$, em que $\mathrm{kn}$ representa a superfície $\mathrm{K}_{1}$ ou $\mathrm{K}_{2}$.

A complexidade estrutural da região de Abadiânia acarretou uma série de dificuldades de correlação estratigráfica e estrutural. Para tanto, foi necessário utilizar, ao mesmo tempo, todos os critérios/elementos de correlação disponíveis e analisar a sua validade local para cada situação (ver Williams 1985). Para permitir o acompanhamento e a visualização das macroestruturas formadas durante o estabelecimento das superfícies deformacionais de $\mathrm{D}_{3}$, construiu-se uma série de perfis aproximadamente perpendiculares à direção da foliação $\mathrm{K}_{1}$ e do eixo $\mathrm{B}^{\mathrm{K} 1}$ (Fig. 2). A construção dos perfis diretamente sobre uma base que delimita a área mapeada possibilitou, além da representação espacial das estruturas geradas por $\mathrm{D}_{3}$, a identificação do que se denominará, nos perfis, de Linhas de Descontinuidade. Essas unhas representam superfícies de deslocamento $\left(\mathrm{Fa}_{\mathrm{k} 1}\right)$ ligadas ao desenvolvimento de $\mathrm{K}_{15}$ e são caracterizadas pela ocorrência de crenulações tipo microcisaIha nos flancos inversos das dobras assimétricas $\mathrm{F}_{\mathrm{Kr}}$ Assim, definida a extensão lateral das diferentes Unhas de descontinuidade, compartimentou-se a área mapeada em segmentos, delimitados por duas superfícies de descontinuidade, com o intuito de isolar os domínios de maior homogeneidade para os elementos estruturais mesoscópicos relacionados à $\mathrm{K}_{1}$ Estes segmentos receberam o nome a partir da superfície que os limita a sul.

A análise de diagramas ir e $\mathrm{p}$, construídos para os diversos segmentos, é a base da metodologia utilizada para a análise estrutural. Os detalhes que cercam a utilização dessa técnica de análise são apresentados por Turner \& Weiss (1963) e por Ramsay (1967). Tais procedimentos permitiram uma ampla discussão sobre o processo deformacional impresso por $\mathrm{K}_{1} \mathrm{e}$ por $\mathrm{K}_{2}$ sobre o posicionamento e o significado estrutural das fases $D_{1}$ e $D_{2}$ e sobre a relação cinemática entre as fases $D_{1}$, $\mathrm{D}_{2} \mathrm{eD}_{3}$.

\section{GEOLOGIA E PETROTRAMAS DEFORMACIONAIS}

A região de Abadiânia sofreu uma evolução estrutural polifásica complexa, onde foram identificadas cinco superfícies deformacionais. Embora os efeitos de superposição estejam regularmente desenvolvidos e distribuídos na área, a complexidade estrutural e a particularidade das estruturas geradas requerem a apresentação de um sumário prévio sobre a articulação e a natureza das superfícies deformacionais que permita um melhor acompanhamento da caracterização das "petrotramas" deformacionais e, posteriormente, da própria análise estrutural. Nesse sentido, foi elaborado o quadro 1, no qual constam a atitude média das superfícies e dos eixos deformacionais, e as estruturas geradas em cada fase deformacional.

O objetivo desta seção não é descrever aprofundadamente a variação da intensidade de transposição, conforme a categorização sugerida por Gray (1977), ou a variação da regularidade de desenvolvimento das foliações, de acordo com as categorias sugeridas por Powell (1979); o objetivo é descrever preferencialmente a trama metamórfico-deformacional final de cada superfície, pois são as características petrográficas destas tramas que permitem, em muitas ocasiões, reconhecer quais as superficies deformacionais envolvidas numa determinada estrutura. Por outro lado, o desenvolvimento do trabalho de análise estrutural mostrou a necessidade e a importância de caracterizar qualitativamente a morfologia geométrica das crenulações; por isso, é feita a distinção entre crenulações tipo microdobra e tipo microcisalha (Hanmer 1979), cujo significado, dentro de cada estrutura, será discutido oportunamente.

Os tipos litológicos da área mapeada (Fig. 3) estão estruturalmente ordenados em uma pseudo-estratigrafia, que resulta de intenso processo de milonitização regional durante a fase deformacional $D_{1}$ Esta pseudo-estratigrafia é composta, do topo para a base, por gnaisses/ xistos porfiroclásticos, por rochas metassedimentares (seqüência gradacional entre moscovita quartzitos, grafita- mosco vita- quartzo xistos e granada-mica-quartzo xistos) e pelos corpos de serpentinito e de rochas máficas. As relações de contato entre os diferentes litotipos são exclusivamente tectônicas por meio da xistosida-

De $\mathrm{S}_{1}$

A xistosidade $S_{l}$ dos gnaisses/ xistos porfiroclásticos está 


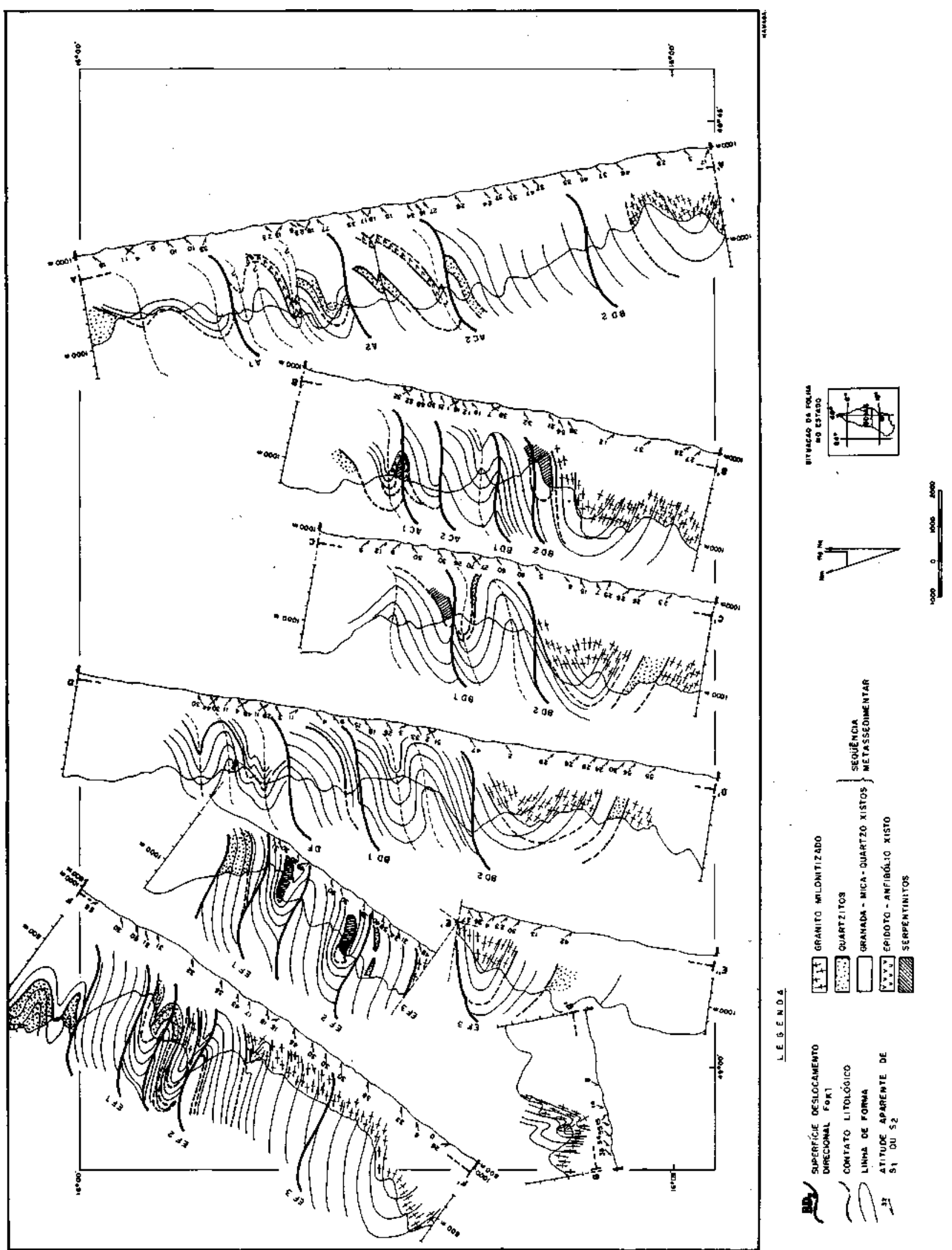

Figura 2 - Mapa de perfis geológico-estruturais da região de Abadiânia. Cada perfil está representado de duas formas: 1. aparte inferior é o perfil sem exagero vertical, no qual estão indicados os mergulhos aparentes dasfoüações $S_{1}$ ou $S_{2} ; 2$. a parte superior é o perfil construído com um exagero vertical de $10 X$, no qual são apresentadas as estruturas deformacionais $F_{K l}$ com mergulhos corrigidos

Figure 2 - Structural profiles map of the Abadiânia region. Each profile are presented in two ways: 1. the lower one is the original profile, where are indicated the apparent dips of the $S_{1}$, or $\mathrm{S}_{2}$ foliations; 2. the upper one is 10-times exaggerated profile, where are presented the deformacional $\mathrm{F}_{\mathrm{K} 1}$ structures with the corrected dips 
Quadro 1 - Resumo da natureza e da orientação média das superficies e dos eixos de deformação desenvolvidos em cada fase de deformação analisada na região de Abadiânia $(G O)$

Chart 1 - A summary of the nature and of the deformational surfaces and axis mean orientations that were developed in each deformational phase in the Abadiânia region (GO)

\begin{tabular}{|c|c|c|c|}
\hline \multicolumn{2}{|c|}{$\begin{array}{ll}\text { Fase } & \text { Superficie } \\
\text { de } & \\
\text { Deformaçäo } & \end{array}$} & \multirow[t]{2}{*}{$\begin{array}{l}\text { Eixos de } \\
\text { Crenulaçăo }\end{array}$} & \multirow{2}{*}{$\begin{array}{l}\text { Observaçסes sobre as } \\
\text { estruturas geradas }\end{array}$} \\
\hline$D_{1}$ & $s_{1}$ & & \\
\hline$D_{2}$ & $S_{2}=200-25 \mathrm{NW}$ & $\mathrm{B}_{1}^{2}=22-300$ & $\begin{array}{l}\text { Dobra } F_{2} \text { recumbente com eixo obliquo à direção } \\
\text { geral de } S_{2} \text {, o que sugere uma geometria em "bainha" } \\
\text { de escala regional }\end{array}$ \\
\hline \multirow[t]{3}{*}{$D_{3}$} & $\mathrm{~K}_{1}=275-50 \mathrm{NE}$ & $\begin{array}{l}B_{1}^{K 1} \\
B_{2}^{K 1} \\
B_{k}=40-056 .\end{array}$ & $\begin{array}{l}\text { Dobras assimetricas } F_{k 1} \text { com geometria kink, com } \\
\text { pequena amplitude, com comprimento de onda de } 1,3 \\
\text { km e com superficie de descontinuidade de } \\
\text { espaçanento de } 0,75-1,3-2,6 \mathrm{~km} \text {, que representam } \\
\text { rampas laterais da lämina de cavalgamento }\end{array}$ \\
\hline & $K_{2}=000-45 E$ & $\begin{array}{l}\mathrm{B}_{1}^{\mathrm{K} 2} \\
\mathrm{~B}_{2}^{\mathrm{K} 2}\end{array}$ & $\begin{array}{l}\text { Dobras assimetricas } F_{k 2} \text { cam a mesma geometria e } \\
\text { amplitude de } F_{k 1} \text {, mas com comprimento de onda de } \\
25-26 \mathrm{~km}\end{array}$ \\
\hline & $\mathrm{K}_{\mathrm{BO}}=045-80 \mathrm{SE}$ & & $\begin{array}{l}\text { Fraturas distensivas com ou sem preenchimento de } \\
\text { quartzo de veio }\end{array}$ \\
\hline
\end{tabular}

marcada pela alternância de bandas formadas essencialmente por porfiroclastos de quartzo, de feldspato e, raramente, de moscovita e de turmalina com bandas onde cristalizam clinozoisita-ou-granada + moscovita+biotita+albita+quartzo. As texturas são miloníticas e de intensidade extremamente variável, o que resulta na formação de um conjunto bandado em diversas escalas, dentro do qual se podem identificar pods miloníticos menos deformados. O protolito inicial $\operatorname{dos}^{\wedge}$ gnaises/xistos porfiroclásticos, como verificado nos pods miloníticos, é uma rocha plutônica de composição granodiorítica portadora de grandes zonas pegmatíticas.

Nas rochas metassedimentares, a xistosidade $\mathrm{S}_{1}$ marca um bandamento milimétrico contínuo que resulta da concentração diferencial de minerais claros e escuros. A paragênese metamórfica varia entre cloritóide+anfibólio-f granada + feldspato + mosco vita+biotita+quartzo e grafita \pm mosco vita+quartzo, de acordo com o litotipo sedimentar predominante. Os porfiroblastos de granada são menores que $3-5 \mathrm{~mm}$ e possuem uma estrutura interna do tipo snow-ball.

As rochas ultramáficas ocorrem em nove pequenos corpos com completa serpentinização e com variáveis transformações metassomáticas de bordo que resultam de sua interação química com as rochas encaixantes (metassedimentos) durante o metamorfismo. Dentre os litotipos que compõem os corpos ultramáficos, os serpentinitos são aqueles que apresentam as características texturais mais marcantes para as superfícies deformacionais e, por isso, têm as suas xistosidades descritas. A xistosidade S-, dos serpentinitos apresenta uma textura lepidoblástica que é marcada por lamelas muito grossas de serpentina; Maltman (1978) denomina este tipo de textura como textura ribbon e relaciona a sua formação com processos de milonitização.

As rochas metabásicas, por sua vez, ocorrem em quatro corpos cuja área aflorante é de uma ordem de grandeza maior do que aquela dos corpos ultramáficos. A sua xistosidade $\mathrm{S}$, possui uma textura nematoblástica bem desenvolvida; porém, em algumas ocasiões, a presença de augen grossos de anfibólio, com formas sigmoidais e com variável desmembramento ao longo das clivagens, permite indicar uma textura ultramilonítica e, também, um protolito gabróico para as rochas básicas. Observações mais sutis permitem verificar que a xistosidade $\mathrm{S}_{1}$ está formada por bandas milimétricas, onde são reconhecidas três paragêneses metamórficas: 1. albita+quartzo, 2. mica branca \pm quartzo \pm albita + epídoto e 3. biotita \pm albita \pm quartzo \pm epídoto + anfibólio. As bandas milimétricas com diferentes paragêneses se agrupam, por sua vez, duas a duas para formar um outro bandamento, agora em escala centímétrica.

A xistosidade $S_{1}$, em qualquer dos litotipos, está completamente desenvolvida; ou seja, não são observadas quaisquer estruturas do tipo clivagem de fratura, ou crenulações que pudessem isolar remanescentes de estruturas planares, ou lineares anteriores. Portanto, a xistosidade $\mathrm{S}_{1}$ constitui o marcador geológico inicial dos estudos de deformação da área. De outro modo, as características texturais e estruturais gerais descritas para a xistosidade $S^{\wedge}$ permitem identificá-la como uma superfície de intensa milonitização regional, que marcou o primeiro episódio deformacional da área (D,).

As superfícies deformacionais posteriores à $\mathrm{S}_{1}$, embora estejam presentes em todos os litotipos, nem sempre são identificadas como xistosidade em todos eles, pois o grau de desenvolvimento daquelas superfícies deformacionais está condicionado à estrutura gerada nas fases $\mathrm{D}_{2} \mathrm{e}_{3}$. O termo final da superposição das superfícies $\mathrm{S}_{2}$ e $\mathrm{K}_{1}$ (as xistosidades) só foram observadas nas rochas metassedimentares e nos corpos ultramáficos; nos demais litotipos, a intensidade de superposição das superfícies $S_{2}, K_{1}$ e $K_{2}$ varia entre crenulações discretas e zonais (Gray 1977) com desenvolvimento bem regular (Powell 1979).

Nesse sentido, o granada-mica-quartzo xisto possui uma 


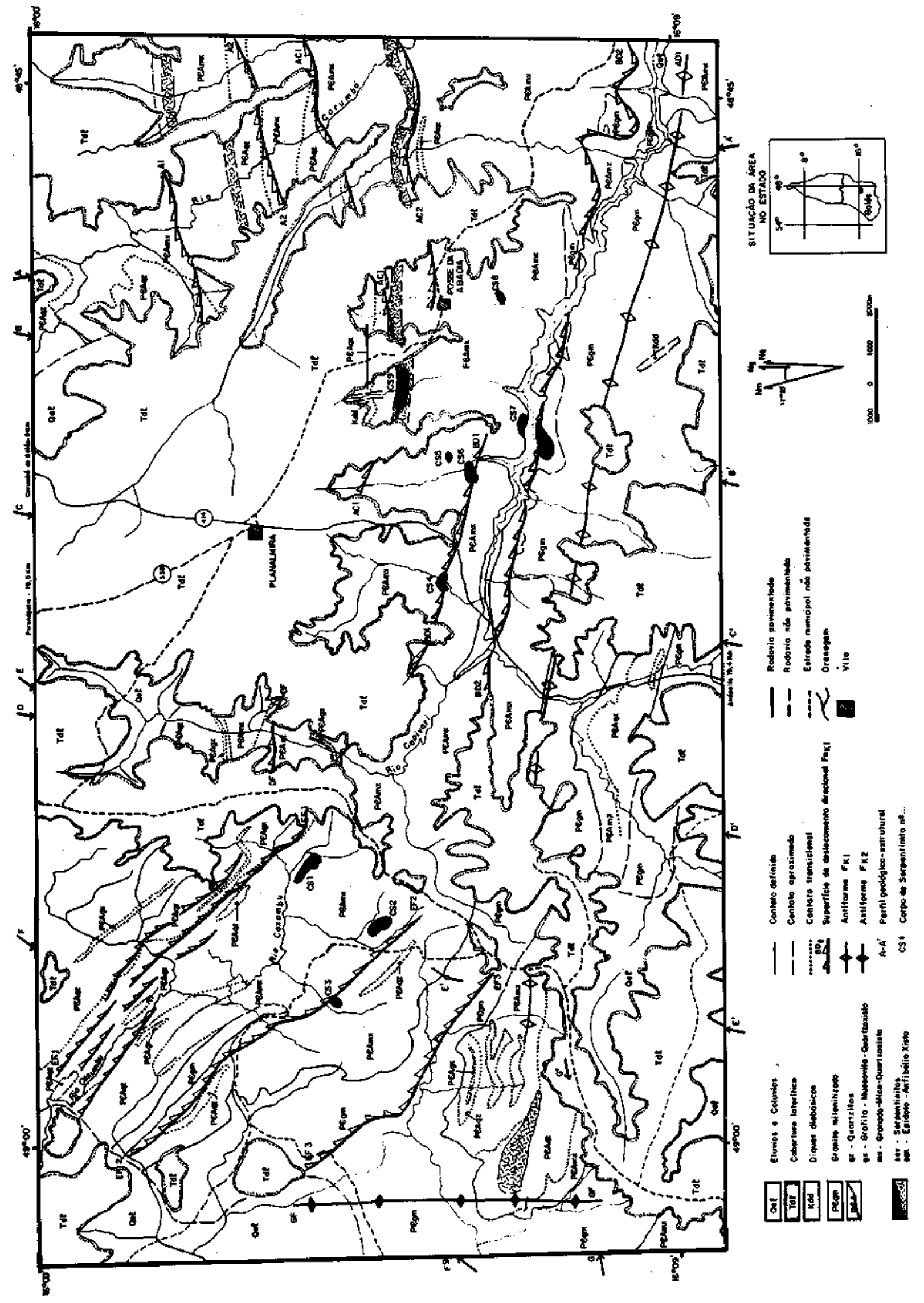


macroestrutura bandada, que é formada pela alternância de zonas onde predomina a trama metamórfico-deformacional $\mathrm{S}_{1}$ com zonas onde predomina a trama S2. Esta macroestrutura bandada sugere que $S_{1}$ foi paralelizada à $S 2$ durante a fase D2 e que a presença de S2, tão bem desenvolvida neste litotipo, é conseqüência da sua localização na parte mais interna das dobras recumbentes $\mathrm{F}_{2}$. A xistosidade $\mathrm{S} 2$, propriamente dita, caracteriza-se por uma textura grano-lepidoblástica grossa, por lentes muito adelgaçadas de minerais félsicos e pela constante presença de vênulas de quartzo, ou de segregações de feldspato+clorita+quartzo na charneira de micro e de mesodobras; as vênulas de quartzo marcam, portanto, microdobras sem raiz que, com o completo desenvolvimento de $\mathrm{S}_{2}$, dão origem a lineações do tipo rods. A paragênese metamórfica recristalizada ao longo de S2, com exceção do anfibólio e do cloritóide, é a mesma que cristalizou ao longo de $\mathrm{S}_{1}$ os porfiroblastos de granada alcançam tamanho da ordem de 10 a $20 \mathrm{~mm}$ durante o estabelecimento de $\mathrm{S}_{2}$ e mostram uma estrutura interna do tipo $\mathrm{S}_{\mathrm{i}} / / \mathrm{S}_{\mathrm{ze}}$.

Os corpos ultramáficos, por estarem alojados no granadamica-quartzo xisto, também possuem uma xistosidade $S_{2}$ muito bem desenvolvida. Esta xistosidade é marcada por uma textura lepidoblástíca fina; microscopicamente, percebe-se que a xistosidade 82 recristaliza lamelas finas de serpentina que transpõem, em grau variável, a serpentina ribbon e que resulta, então, numa textura denominada bladed-mat por Maltman (1978).

Das superfícies conjugadas da fase $\mathrm{D}_{3}, \mathrm{~K}_{1}$ é a mais marcada nesta região, porque está posicionada de acordo com as rampas laterais da lâmina de cavalgamento. Esse mesmo controle de intensidade de transposição está envolvido na manifestação da xistosidade $K_{1}$ : pois ela somente foi identificada no segmento EF1, que representa a fusão das superfícies de descontinuidade DF e BD1, e numa pequena superfície de descontínuidade interna no segmento EF2. A xistosidade $\mathrm{K}_{1}$ está marcada por um bandamento diferenciado grosso $(2 \mathrm{~mm}$ - $4 \mathrm{~mm}$ ) no qual ocorre a recristalização da mesma paragênese metamórfica observada ao longo de $\mathrm{S}_{2}$; os porfiroblastos de granada das fases anteriores são rompidos e ocorre a recristalização de novos porfiroblastos com estrutura interna tipo snow-ball.

Os corpos ultramáficos que foram cortados por superfícies de descontinuidade $\mathrm{Fa}_{\mathrm{K} 1}$ mostram, normalmente, o desenvolvimento de uma xistosidade $K_{1}$, que também possui textura lepidoblástíca fina devido à recristalização de lamelas finas de serpentina e à formação de uma textura bladed-mat.

A petrografia de cada litotipo revelou que houve recorrência na cristalização de uma mesma paragênese metamórfica índice em todas as fases de deformação; portanto, é indicado que todo o processo deformacional impresso nos litotipos desta região ocorreu dentro de idênticas condições de temperatura e de pressão. A investigação de um campo de estabilidade comum da paragênese de cada litotipo forneceu temperaturas dentro do intervalo de $550^{\circ} \mathrm{C}$ e $600^{\circ} \mathrm{C}$ e pressões acima de 5 kbar para um metamorfismo que ocorreu sob condições de média a alta $\mathrm{FO}_{2}$ (Strieder 1989).

FASE DEFORMACIONAL $\mathbf{D}_{3}$ Em toda a região próxima ao paralelo $16^{\circ} 00^{\prime} \mathrm{S}$, tanto $\mathrm{K}_{1}$ quanto $\mathrm{K}_{2}$ desenvolvem dobras assimétricas de pequena amplitude; porém, enquanto o comprimento de onda de $\mathrm{K}_{1}$ é de aproximadamente $1,3 \mathrm{~km}$, o comprimento de onda de $K_{2}$ é da ordem de $25-26 \mathrm{~km}$. As superfícies de descontinuidade ligadas à $\mathrm{K}_{1}$ localizam-se no flanco inverso das dobras $\mathrm{F}_{\mathrm{K} 1}$ e, desta forma, têm um espaçamento de $0,75-1,3-2,6 \mathrm{~km}$.

$\mathrm{Na}$ figura 4, é possível perceber, a partir da orientação das superfícies de descontinuidade $\left(\mathrm{Fa}_{\mathrm{K} 1}\right)$, que a atitude de $\mathrm{K}_{1}$ sofre inflexão para NW no lado oeste da área. Isto é o resultado da superposição de $\mathrm{K}_{2}$, que ocorre ou como simples fraturas de espaçamento variável (lado leste), ou como cÜvagem de crenulação (microdobra, ou microcisalha no lado oeste). Assim, toda a região de Abadiânia é deformacionalmente homogênea com relação a $K_{2}$, enquanto as suas partes leste e oeste são, separadamente, domínios homogêneos com relação a $\mathrm{K}_{1}$.

A partir destas considerações, a área é dividida em oito segmentos que recebem denominações diferentes para as partes leste e oeste e, então, a análise estrutural de DS é desenvolvida em três etapas: a. é analisada a natureza da superfície $\mathrm{K}_{1}$ com base nos dados estruturais obtidos nos segmentos da parte leste, b. são analisados os efeitos da inflexão N W da superfície $K_{1}$ e c. é analisada a natureza da superfície K2 a partir da análise estrutural da inflexão de $\mathrm{K}_{1}$ e de $\mathrm{B}^{\mathrm{K1}}$.

ANÁLISE DE K $K_{1}$ NA PARTE LESTE A natureza de $\mathrm{K}_{1}$ é obtida a partir do afloramento em granada-mica-quartzo xisto que está localizado na zona de charneira de antiforme $\mathrm{F}_{\mathrm{K} 1}$, junto ao Corpo de Serpentinito $\mathrm{n}^{\mathrm{o}} 9$ (CS 9). Nesse afloramento, foi possível obter uma quantidade razoável de medidas de planoaxial e de eixo de microdobras $\mathrm{F}_{2}$ em apenas um dos lados perpendiculares ao eixo $\mathrm{B}^{\mathrm{K} 1}$, o que garante a homogeneidade das medidas com relação à deformação causada por $\mathrm{K}_{1}$, e possibilita a sua utilização para avaliar o mecanismo de deformação que atuou no desenvolvimento desta superfície. $\mathrm{O}$ diagrama TT e $\mid 5$ destas medidas é apresentado na figura 5 e mostra que a dispersão de $\mathrm{B}^{\wedge}$ se adapta muito bem a um grande círculo de atitude média $204-20 \mathrm{NW}$, embora esta dispersão não o abranja completamente; assim, este padrão de dispersão indica um mecanismo de cisalhamento simples para o desenvolvimento de $\mathrm{Kj}$.

A generalização desse procedimento para os dados individualizados de cada segmento da parte leste (Fig. 6) mostra uma boa concordância com o padrão de dispersão do afloramento discutido acima. A superfície média de melhor ajuste para a dispersão de $\mathrm{B}^{\wedge}$, considerado o conjunto destes segmentos, tem atitude $200-25 \mathrm{NW}$. A interpretação do cisalhamento simples como o mecanismo responsável pelo desenvolvimento de $\mathrm{K}_{1}$ e das estruturas relacionadas é um ponto de conseqüências importantes e deve merecer atenção na medida em que a dispersão das lineações $\mathrm{B}^{\wedge}$ não abrange completamente o grande círculo médio que foi indicado. A pequena amplitude das dobras, a pequena extensão da zona de charneira e a descontinuidade dos afloramentos dificultaram a localização de outros afloramentos com as características daquele apresentado acima. A identificação de crenulações e de mesodobras concêntricas e chevron (Johnson \& Ellen 1974) poderia sugerir que as dispersões da lineação Bf se fizessem num pequeno círculo com eixo centrado em $\mathrm{B}^{\mathrm{K} 1}$, porque são dobras causadas por mecanismo de flambagem. No entanto, todos os diagramas ir - p construídos para os segmentos da parte leste mostram consistência quanto ao grande círculo locado e apresentam uma variável amplitude de dispersão da lineação $\mathrm{B}^{\wedge}$; em nenhum destes diagramas é possível locar um pequeno círculo para a dispersão de $\mathrm{B}_{1}{ }^{2}$. Assim, a geometria das crenulações deve estar refletindo a natureza das anisotropias da trama envolvida na^eformação por $K_{1}$ (Gray 1979) e não a geometria da macroestrutura onde ocorrem. Portanto, é mantida a interpretação dada ao mecanismo de deformação que gera a superfície $\mathrm{K}_{1}$.

Caracterizado o mecanismo de cisalhamento simples na geração das estruturas ligadas à $\mathrm{K}_{1}$ ? pode-se determinar a posição espacial dos eixos cinemáticos principais desta deformação por meio dos procedimentos delineados por Ramsay (1967). A utilização de tais procedimentos nas figuras 5 e 6 mostra que a orientação dos eixos $\mathrm{B}^{\mathrm{k} 1}$ está muito próxima da direção de cisalhamento da superfície $\mathrm{K}_{1}\left(\mathbf{a}_{\mathrm{K} 1}\right)$; isto tem como conseqüência a pequena amplitude das dobras geradas e está registrado nos perfis da figura 2. Além do mais, pelo exame das figuras anteriores, percebe-se que o eixo $\mathrm{B}^{\mathrm{k} 1}$ médio e a direção $\mathbf{a}_{\mathbf{K} 1}$ de cisalhamento para cada segmento estão aproximadamente contidas na superfície em que dispersam $\mathrm{B}_{1}{ }^{2}$. 


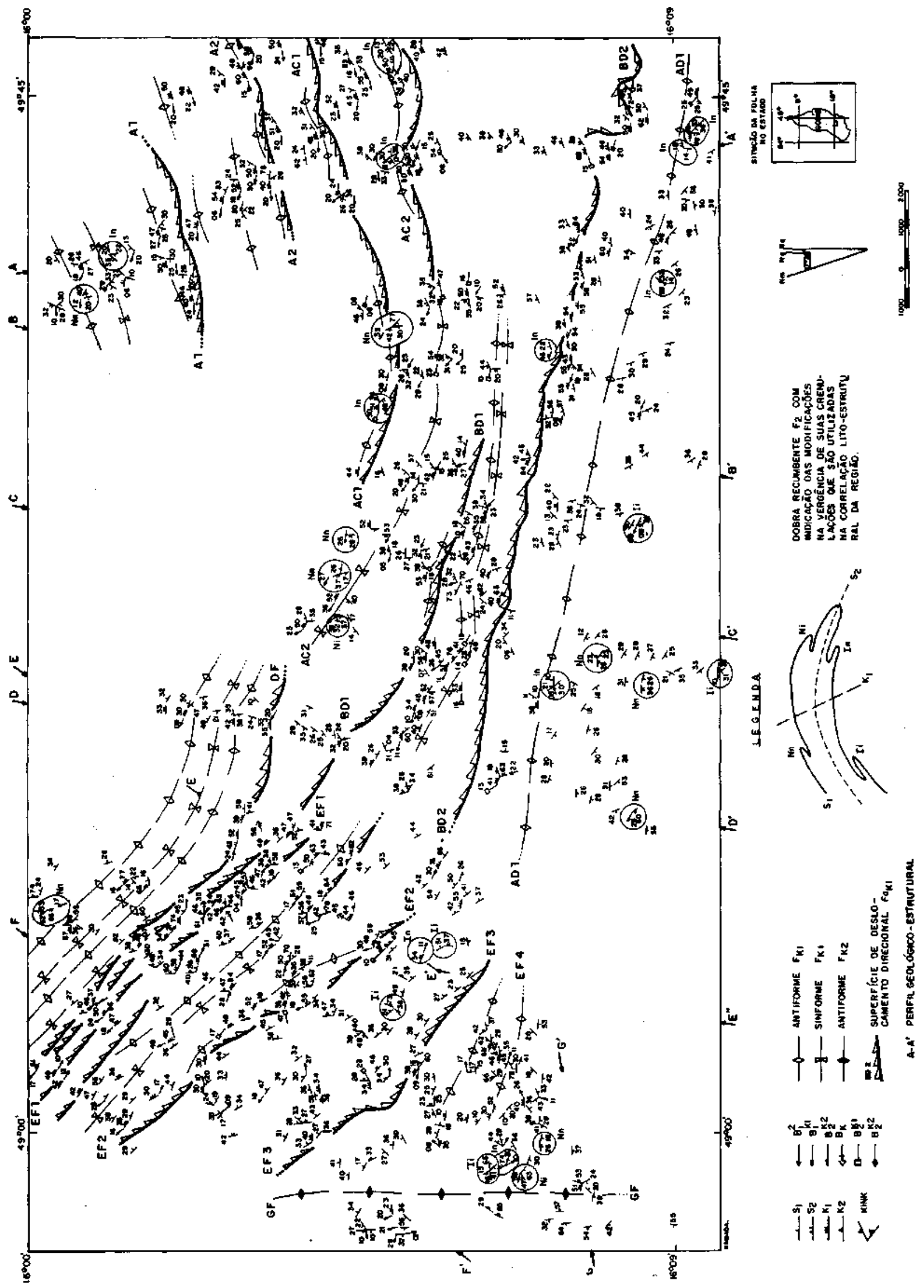



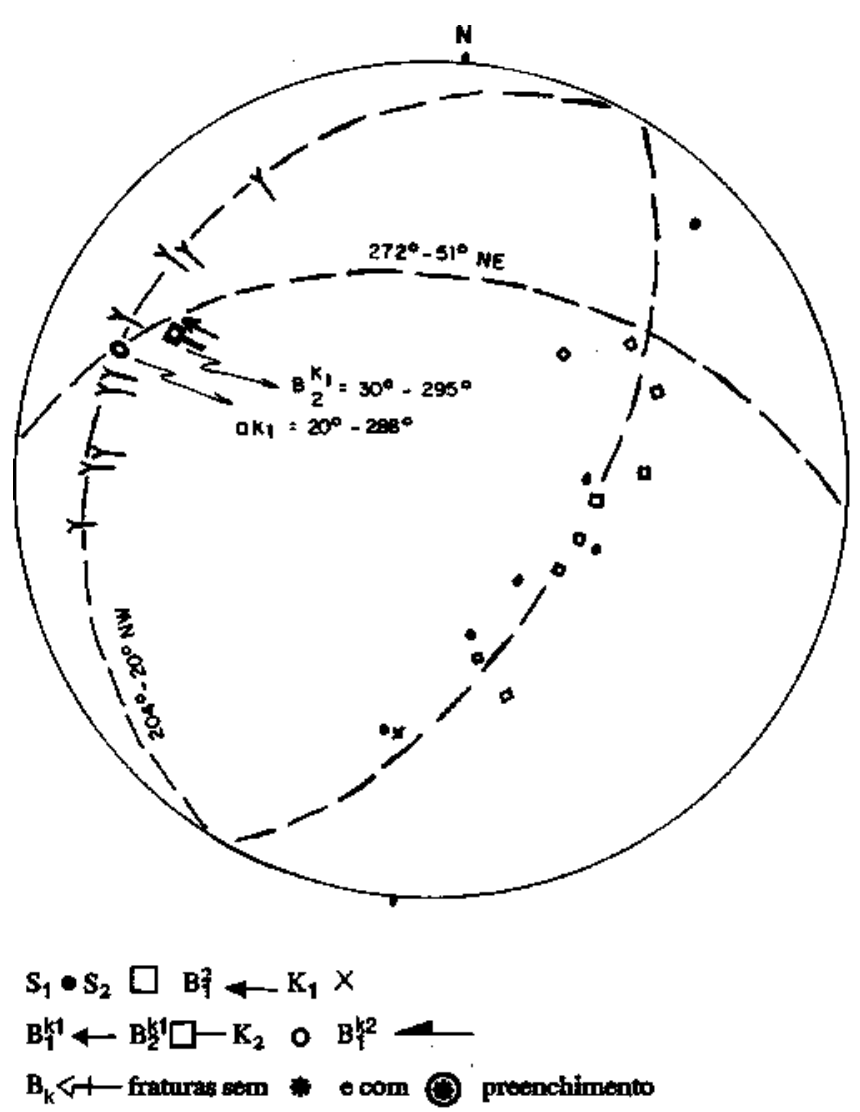

Figura 5 - Diagrama $\pi$ e $\beta$ da deformagäo de $S_{1}$ por $S_{2}$ (Aflor. $P$. 102B; $B_{1}^{2} \leftarrow$ le de $S_{2}$ por $K_{1}$ (Aflor. $P$. 104G; $B_{1}^{2}>-$ ). $O$ diagrama representa o hemisferio inferior do estereogramo de igual-área

Figuro $S-z-\beta$ dingrim for deformation of $S_{1}$ by $S_{2}$ (cuterop $P$. $102 B$; $B$; $\leftarrow$ ) and of $S_{2}$ by $K_{1}$ (outerop $P, 104 G ; B_{7}^{2} \succ-$ ). The diagram is the lower hemisphere of the equal-area net.

A estrutura interna de cada segmento sofre modificações laterais que podem ser acompanhadas pela observação dos perfis da figura 2. Assim, o Segmento AC 1 não parece, ao nív£l de exposição atual, estar marcado por uma superfície de dèscontinuidade no lado leste da área; porém, a oeste (perfil B-B', Fig. 2), a superfície de dèscontinuidade que o individualiza ganha contorno mais nítido e, muito provavelmente, se estende sob o Chapadão Laterítico de Planalmira para encontrar a Superfície de Dèscontinuidade DF. A Superfície de Dèscontinuidade AC2, ao contrário, perde expressão em direção a oeste, onde se localiza uma grande sinforme $F_{k 1}$, que se estende do Córrego Alvarenga até o Córrego Quilombo.

A Superfície de Dèscontinuidade BD2 é a de maior expressão na área e tem continuidade para oeste como EF2. Na parte mais a leste da área, o segmento individualizado por esta superfície não mostra evidência de qualquer dobramento; contudo, para oeste, a disposição espacial de $\mathrm{S}_{1}$ e Sá sugere, inicialmente, uma estrutura sinforme (Córrego d'Abadia), que passa para um conjunto sinforme-antiforme-sinforme (Córrego Alvarenga) cuja amplitude aumenta gradativamente.

A Superfície de Dèscontinuidade BD1 é individualizada a partir do flanco normal da antiforme do Segmento BD2 (altura do Córrego Arribação) e se estende para oeste até se unir com a Superfície de Dèscontinuidade DF e dar origem a um intenso desenvolvimento de xistosidade $\mathrm{K}_{\mathrm{t}}$ e a estruturas muito particulares no Segmento EF1.

O Segmento ADI constitui uma grande dobra antiforme que limita a parte sul da área (Fig. 2) e que se estende para oeste (Segmento EF4 - GF) onde a interferência de $\mathrm{K}_{1}$ e Ka produz um padrão do tipo $1 \rightarrow 2$ (Ramsay 1967). Assim, os procedimentos de análise estrutuial (Turner \& Weiss 1963) exigem a subdivisão adicional do Segmento EF4-GF; ou seja, a estrutura dê interferência foi desmembrada em subdomínios leste, sudoeste e noroeste (Fig. 7) com relação à superfície deformacional $\mathrm{S}_{15}$ de modo a se obter uma melhor homogeneidade para os elementos estruturais medidos no segmento e se realizar uma melhor análise da estrutura. A figura 7C mostra, por análise comparada com as figuras $7 \mathrm{~A}$ e $7 \mathrm{~B}$, a natureza da dispersão dos elementos planares e os lineares da segunda fase deformacional no Segmento EF4-GF.

Em muitas ocasiões, tem-se demonstrado a utilidade de mesoestruturas na elucidação, por correlação ou por semelhança, do padrão desenvolvido pelas macroestruturas deformacionais. Este parece ser o caso da mesoestrutura apresentada na figura 8, que ocorre em afloramento no leito do Rio Corumbá, onde uma dobra de $F_{k 1}$ está superimposta a mesodobras assimétricas $\mathrm{F}_{2}$ (Fig. 8A). Mais especificamente, a mesoestrutura está relacionada à charneira de uma mesodobra $\mathrm{F}_{2}$ (Fig. 8B e 8C); as fraturas observadas na mesoestrutura possuem a mesma orientação da superfície $K_{1}$ têm forma sigmoidal e dão origem a dobras e a inflexões de $S_{1}$ num padrão semelhante àqueles observados nos diversos segmentos individualizados na região (comparar Fig. 8B e 8C com Fig. 2). O comportamento dos elementos estruturais do afloramento é apresentado na figura $8 \mathrm{D}$ e mostra-se concordante com os padrões observados para os diversos segmentos individualizados na parte leste da área.

Análise de $K_{1}$ na parte oes+e Nos segmentos da parte leste da área e nos segmentos DF e EF4-GF, $K_{1}$ foi medida apenas como planoaxial de crenulações tipo microdobra, ou como superfície de deslizamento em crenulações tipo microcisalha. Contudo, $\mathrm{K}_{1}$ está marcada como uma intensa xistosidade com características de bandamento diferenciado grosso principalmente no Segmento EF1; a intensificação de $K_{1}$, neste segmento, é o resultado da fusão de duas superfícies de dèscontinuidade (BD1 e DF) e gera diversas mesoestruturas agrupadas da seguinte maneira:

- mesolitons de crenulação (Fig. 9B): possuem tamanho que -varia entre $30 \mathrm{~cm}$ e $150 \mathrm{~cm}$;

- boudins estabelecidos pela existência de um discreto contraste de ductilidade, que ocasiona o rompimento local da estrutura, a deposição de quartzo e a formação de dobra surreica no neck do mesmo (Figs. 9A e 9C);

- boudins que estão estabelecidos em locais onde inexiste qualquer contraste de ductilidade e que levam a xistosidade $\mathrm{K}_{1}$ a assumir uma forma anastomosada (Fig. 10), com rompimento incipiente (Fig. 11), semelhante a uma estrutura tipo pinch-and-swell.

Associadas à "boudinagem", é possível medir superfícies conjugadas ( kinks normais, ou microcisalhamentos: Figs. 9 e 12), cujo aparecimento, conjunto ou isolado, depende apenas do grau de anisotropia da rocha considerada (Cosgrove 1976). Estes kinks mostram uma perfeita simetria ortorrômbica com relação à xistosidade $\mathrm{K}_{1}$ (bissetriz aguda dos planos conjugados) e aos eixos de boudinagem (Fig. 13) e indicam que $\mathrm{K}_{1}$ sofreu ou estiramento ao longo de sua superfície, ou compressão perpendicular a esta mesma superfície.

De ocorrência mais restrita ao longo deste segmento, também se pode individualizar kinks reversos (nomenclatura de Cosgrove 1976), apresentados na figura 12, que tem a mesma simetria e posição dos planos conjugados do $J d n k$ normal (Fig. 13); contudo, neste caso, indicam uma compressão, segundo a direção anteriormente caracterizada, como de estiramento. A bissetriz obtusa dos dois tipos de kink é marcada por fraturas distensivas com ou sem preenchimento (Figs. 10, 11 e 12$)$.

A atitude média de $\mathrm{K}$ \} na parte oeste é 310-50NE e as li- 


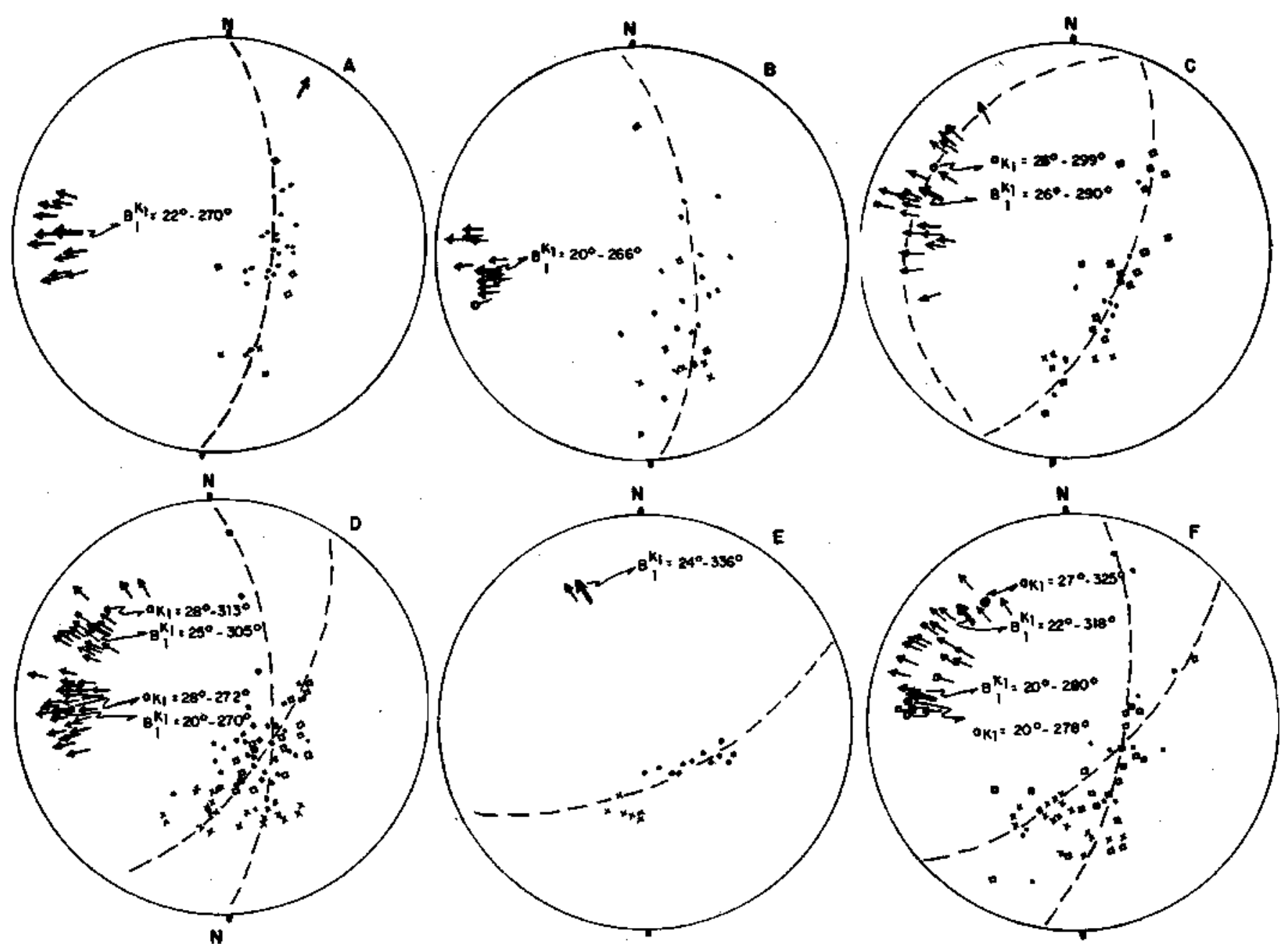

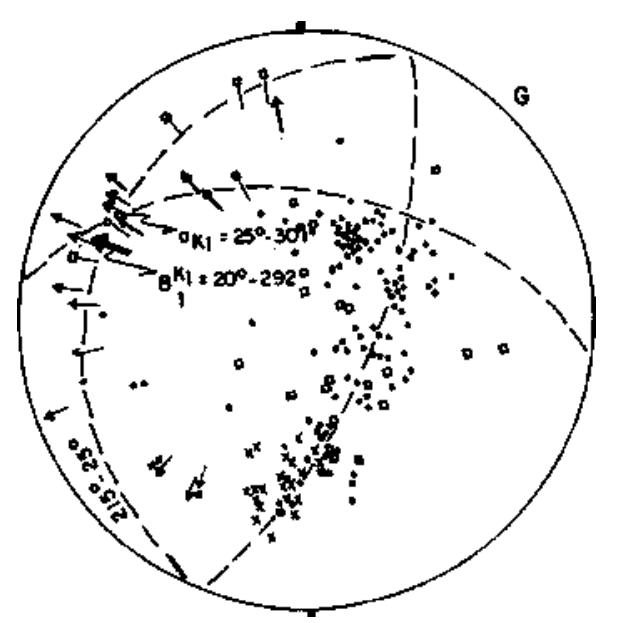

neações $\mathrm{B}^{\mathrm{k} 1}$, dispostas predominantemente suborizontalizadas, definem dois polos simetricamente opostos, como resultado da superposição local de Ka (Fig. 14). Porém, o padrão de dispersão das lineações $B^{\mathrm{k} 1}$ nos Segmentos EF1, EF2 e EF3 é essencialmente diverso daquele dos segmentos anteriores: a dispersão se dá ao longo da superfície média $\mathrm{K}_{1}$ em direção ao eixo do conjunto kink/boudin. Este efeito é produzido pela progressiva reorientação de $S_{1} / / S_{2}$ para a posição de $K_{1}$ infletida, que, durante a transposição, gera crenulações cujo eixo se aproxima daquele do conjunto kink/boudin .

O segmento EF2 é visto como uma continuidade do Seg- mento BD2, que, ao nível de exposição atual, preserva a antiforme colocada junto à superfície de descontinuidade. A superfície K, neste setor, está fortemente impressa na forma de crenulações com tranposições locais. Nas proximidades do Corpo de Serpentinito CS 1, a antiforme interna do segmento está diretamente sobre o flanco normal da antiforme colocada junto à superfície de descontinuidade, o que caracteriza a transposição do flanco inverso, a omissão da sinforme e a existência de uma pequena superfície de descontinuidade dentro do Segmento EF2.

No segmento EF3, por outro lado, não se definiu qualquer 

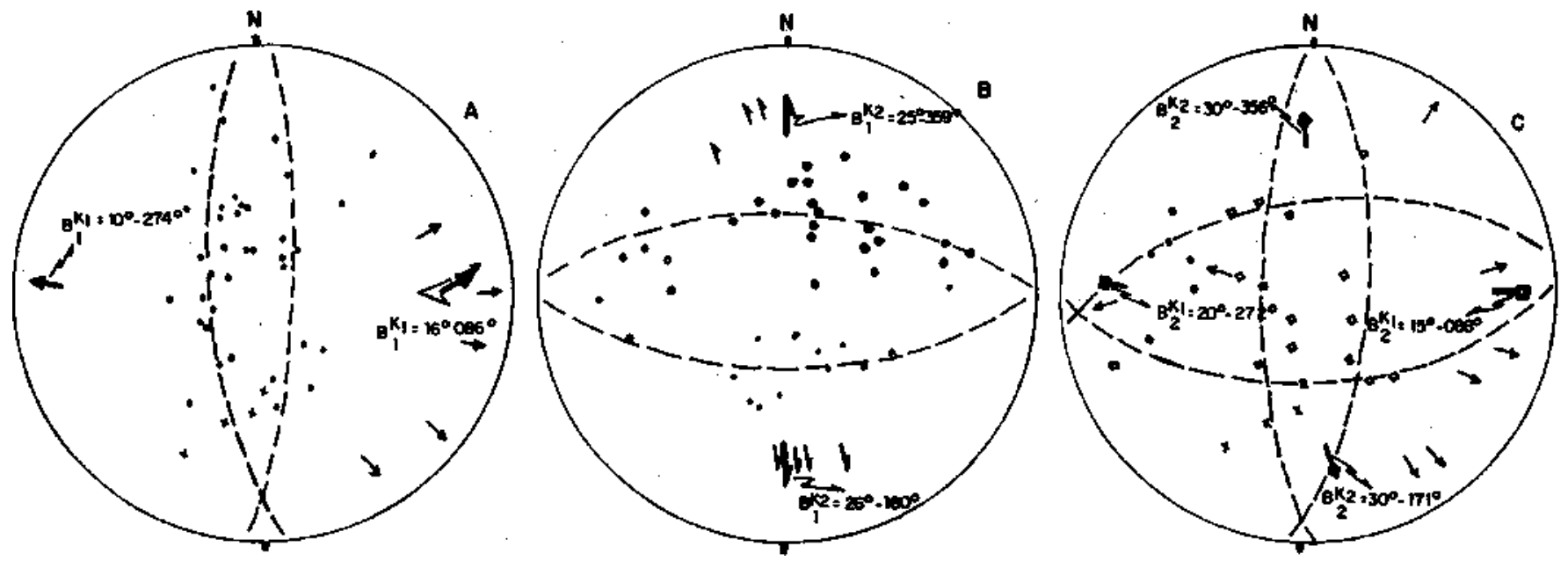

Figura 7 - Diagramas ir e P da deformação no Segmento EF4-GF: A. deformação de $S^{\wedge}$ por $K^{\wedge}$ no subdomínio leste do segmento; B. deformação de $\mathrm{S}_{1}$ por $K_{2}$ nos subdomínios sudoeste $\left(S_{1}=\bullet\right)$ e noroeste $\left(S_{1}=\bullet\right)$ do segmento; C. deformação de $S_{2}$ por $K_{1} e$ por $K_{2}$ no segmento como um todo. Demais símbolos, como os da figura 5

Figure 7 - ir and P diagrams of the deformation in the EF4-GF: Segment: A. deformation of $\mathrm{S}_{1}$ by $K$, in the east sub-domain; B. deformation of $\mathrm{S}_{\mathrm{t}}$ by $\mathrm{K}_{2}$ in the southwest $(\mathrm{St}=\bullet)$ and in the northwest $(S I=\bullet)$ sub-domains; C. deformation of $\mathrm{S}_{2}$ by $K_{l}$ and by $\mathrm{K}_{2}$ in the segment on the whole. The others symbols are as figure 5

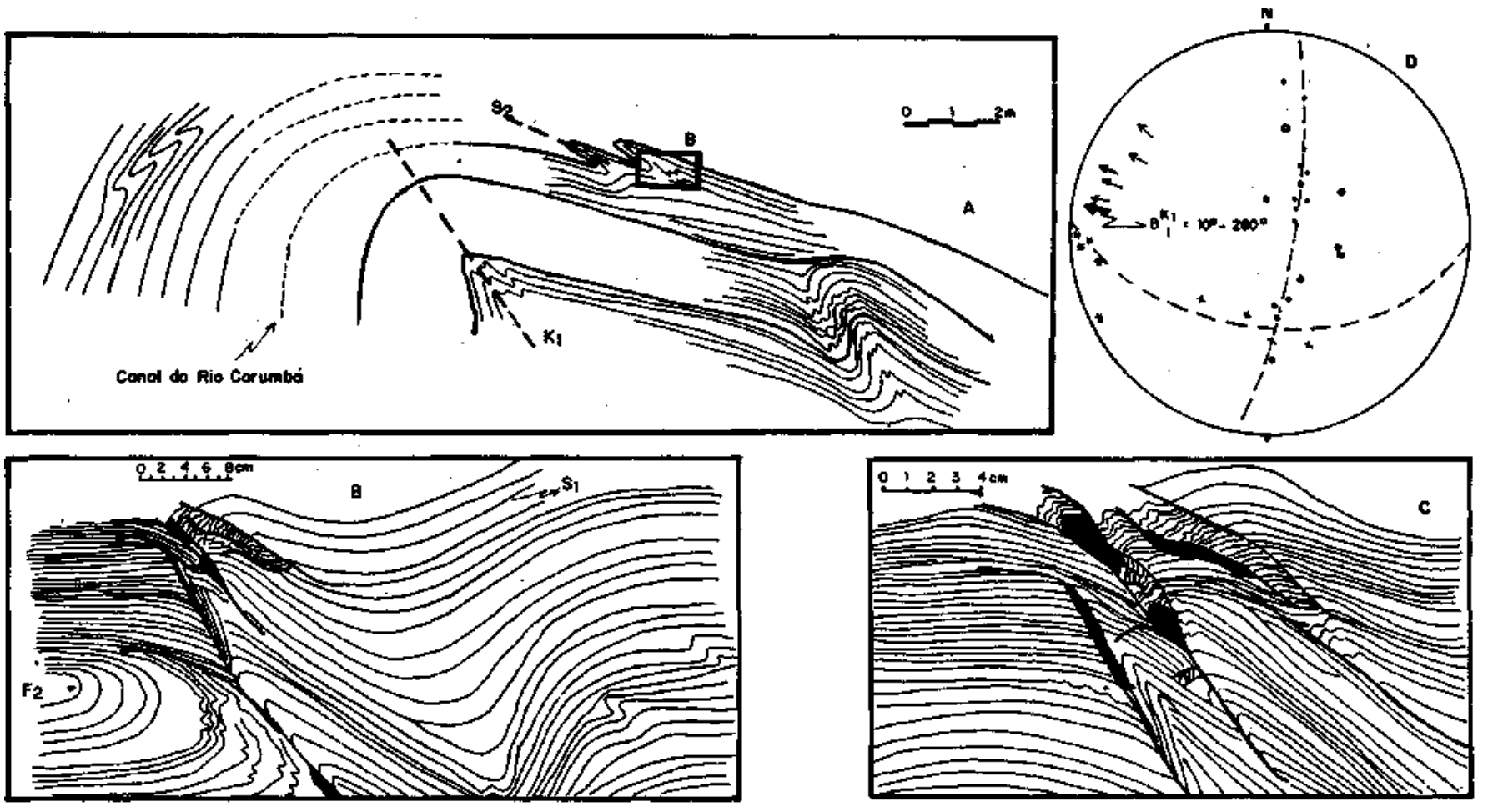

Figura 8 - Estruturas deformacionais identificadas no Afloramento P. 97F, localizado no leito do Rio Corumbá. A. Dobra F $F_{M} q u$ envolve mesodobras $F_{2}$ assimétricas deflanco invertido. $\mathbf{B} e \mathbf{C}$. Representam o mesmo detalhe, em escala diferente, de mesóestrutura $\mathrm{F}_{\mathrm{k} 1}$ relacionada à charneira de dobras $F_{2} ; K 1$ manifesta-se como fraturas inversas que causam imbricações e dobras da trama deformacional de $5_{1}$ em vários padrões geométricos. D. Diagrama ir e p da deformação de $S_{1}$ e $S_{2}$ por $K^{\wedge}$ e de $K_{3}$ por $K_{2}$ no Afloramento $P$. 97F. Também são apresentadas as medidas de $\left(\bullet S_{1}\right.$ deformada por $S_{2}$ para comparação com a deformação produzida por K). Demais símbolos iguais àqueles da figura 5

Figure 8 - Defonnational structures identified in the P. 97F outcrop that are localized in the Corumbá River. A. $\mathrm{F}_{\mathrm{M}}$ fold upon assimetric $\mathrm{F}_{2}$ mesofolds of the inverted limb. B and C. are the same details, but in different scales, of a $F_{M}$ meso-structure related to the hinge of a $F_{2}$ fold; the $K_{1}$ surface are present as inverse fractures that cause imbricatrions and folding of the original $\mathrm{S}_{1}$ deformational fabric. D. $\Pi$ and $\beta$ diagrams of the deformation of $S$-। and $\mathrm{S}_{2}$ by $\mathrm{K} 1$ and of $\mathrm{K}$ ! by $\mathrm{K}_{2}$ in the P. 97F outcrop; some data of the deformation of $\mathrm{S}_{1}(\bullet)$ by $\mathrm{S}_{2}$ are also shov $\mathrm{n}$ to compare with deformation produced by $\mathrm{K}_{1}$ surface. The other symbols are the same as figure 5 


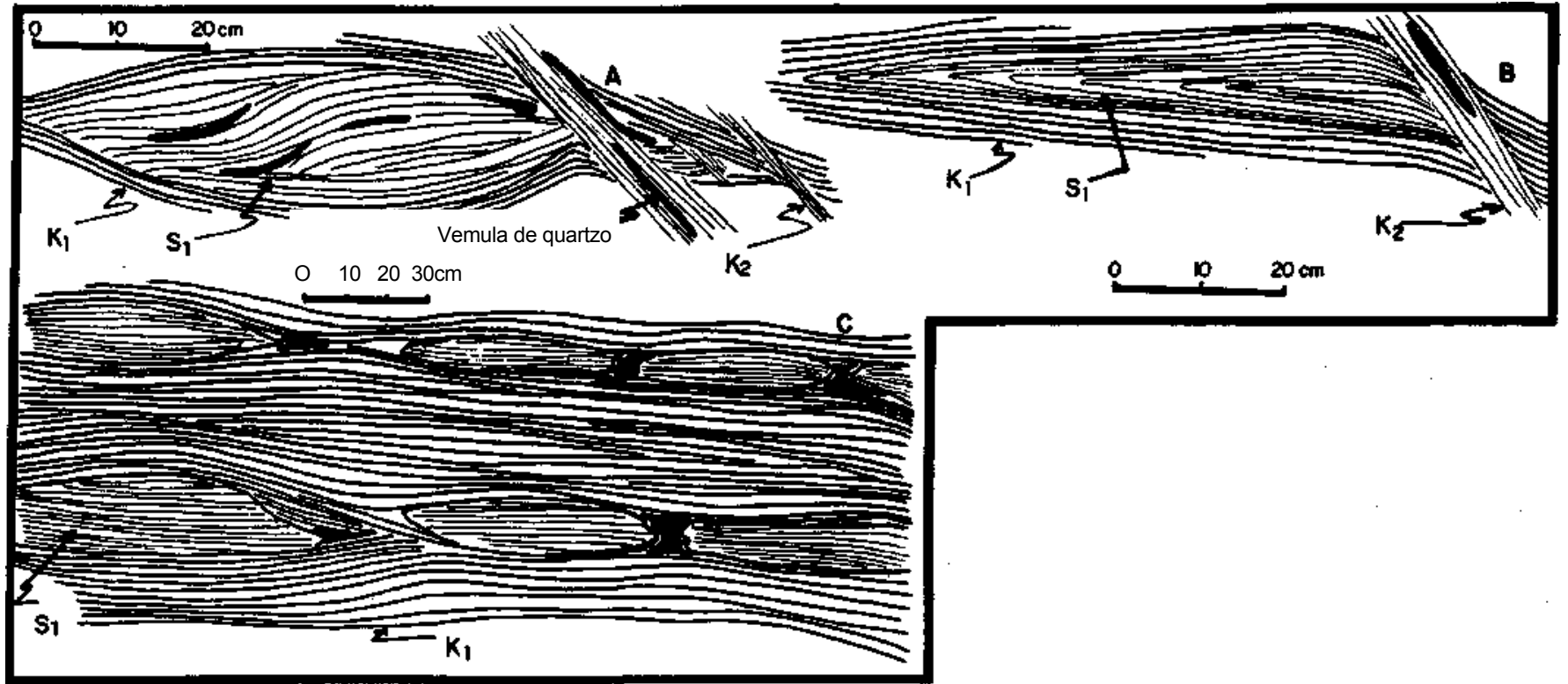

Figura 9 - Estruturas mesolitons de transposiçäo identificadas no Afloramento P. SIC. A. Transposiçáo da trama metamórico-deformacional de $S_{1}$ por meio de "boudinagem" durante o desenvolvimento da trama de $K_{1}$. B. Mesolitons de dobra $F_{1}^{k 1}$; notar que a presença da superficie $K_{2}$ bem desenvolvida gera crenulaçâo do tipo cisalha. C. Boudins sobre a trama metamorfico-deformacional de $S_{1}$ como resultado da transposiçäo por $K_{1}$

Figure 9 - Traneposition mesolithons structures identified in the P.51C outerop. A. Transposition of the $S_{1}$ deformational fabric through boudinage during the development of the $K_{1}$ deformational fabric. B. Fk' fold mesolithon; notice that the presence of the $K_{2}$ unface generate a microshear-type creaulation. $C$. Boudins blished upon $S$, deformntional fabric a resolt of the transponition by $K_{1}$

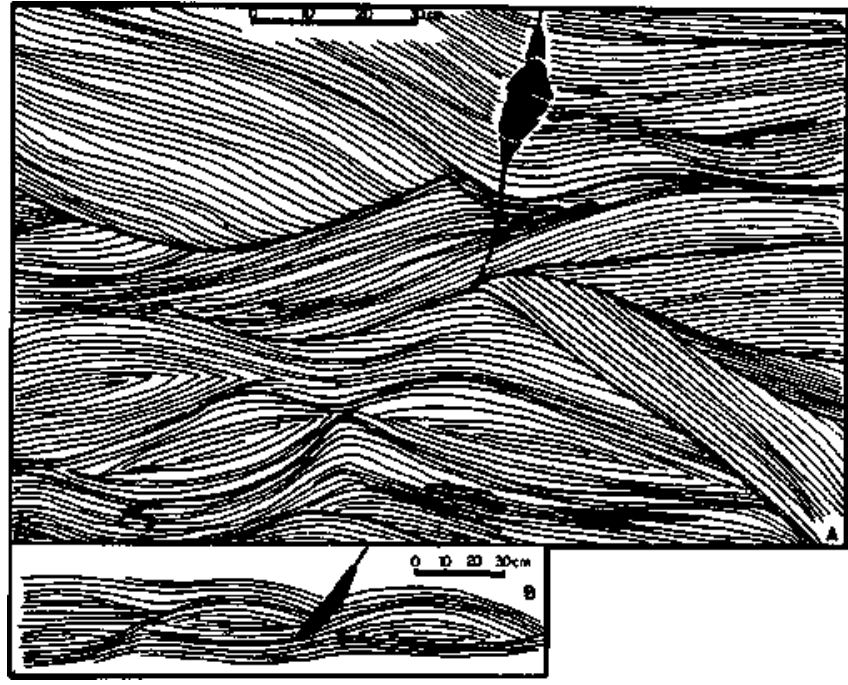

Figura 10 - Padrão anastomosado da xistosidade K1 sobre moscovita quartzito identificado em duas partes (A e B) do Afloramento P. 52E. Notar as fraturas distensivas com depçsição de quartzo localizadas nos adelgaçamentos da mesoestrutura

Figure 10 - Anastomosed aspect of the $\mathrm{K}_{1}$ schistosity on muscovite quartzite identified in two parts (A and B) of the P.52E outcrop. Notice the distenaive quartz-filled fractures localized on the necking of the meso-structure

dobra de maior expressão; dobras muito suaves e assimétricas são verificadas no gnaisse porfiroclástico exposto na base sul do Morro Santana e podem ser atribuídas a cisalhamento de contato (layer-parallel shear) durante os deslocamentos na superfície de descontinuidade EF2 que está estruturalmente 250

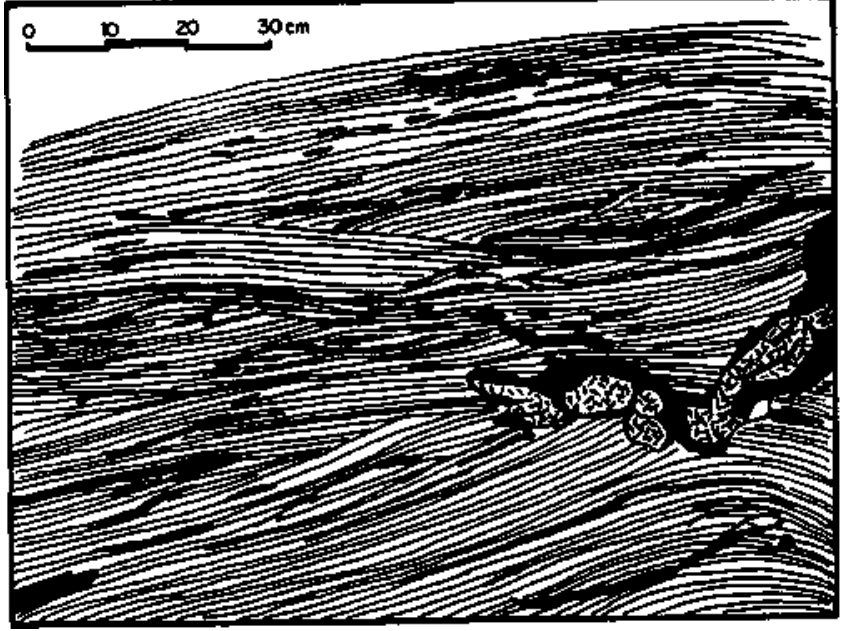

Figura 11 - Padrão anastomosado com estrangulamento da xistosidade $K_{1}$ em granada-mica-quartzo xisto no Afloramento P. 55E. Notar a segregação de feldspato+clorita+quartzo no neck do estrangulamento

Figure 11 - Anastomosed aspectw ith the necking of the $\mathrm{K}^{\wedge}$ schistosity on gamet-mica-quartz schist (P.55E outcrop). Notice the feldspar+chlorite+quartz segregation on the neck

sobreposta. Assim, o segmento tem estrutura mais ou menos planar (isto é, sem dobras), com adelgaçamentos locais pouco desenvolvidos.

NATUREZA DA SUPERFÍCIE $\mathrm{K}_{2}$ As superfícies de kink associadas aos boudins, descritos acima, podem aparecer isoladamente impressas sobre $\mathrm{K}_{\mathrm{t}}$ infletida, ou sobre $\mathrm{S}_{1} / / \mathrm{S}_{2}$ transpostos. A orientação espacial destas duas superfícies é 


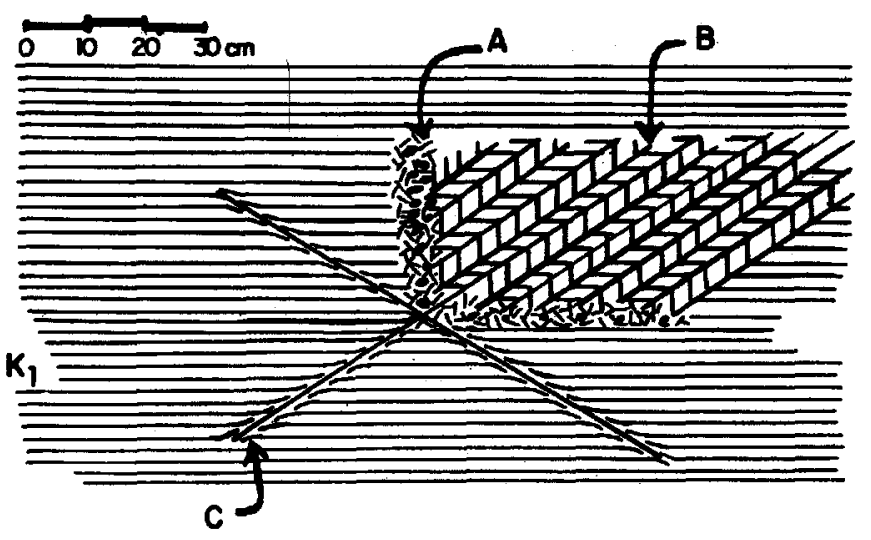

Figura 12 - Meso-estrutura desenvolvida sobre a xistosidade $K_{1}$ no Afloramento $P .52 F$, onde estäo relacionados os dois $t i$ pos de kink. Notar o posicionamento das segregaçōes de feldspato + clorita + quartzo ao longo de fraturas distensivas, que marcam a bissetriz obtusa $(B O)$ dos planos conjugados $e$ da superficie $K_{1}$. Legenda: A. segregação; B. kink reverso; C. kink norimal

Figure 12 - Meso-structure developed upon the $K_{1}$ schistosity on the $P$. 52F outcrop, w here the two types of kinks are related. Notice the position occupied by the feldspar + chlorite + quartz segregation: it is in distensive fracture that marks the obtuse bisector of the conjugated surfaces and along $K_{1}$ fabric. Legend: A. segregation; B. reverse-type kink; $C$. normal-type kink

semelhante à orientação espacial de $\mathrm{K}_{2}$ e de $\mathrm{K}_{1}$ regionais (Fig.14A). Estas duas observações sugerem uma relação bastante ultima entre as superfícies kink medidas e aquelas relacionadas à deformação regional. Para a verificação desta correlação, aprofunda-se a análise deformacional de $\mathrm{K}_{2}$ pela utilização dos mesmos procedimentos adotados na análise de $\mathrm{K}_{1}$ A análise deformacional de $K_{2}$ é realizada em termos regionais, pois os registros de campo indicam-na como a última superfície deformacional impressa na região e, deste modo, não há necessidade de se dispor de um afloramento único no qual se pudesse medir uma quantidade razoável de eixos $\mathrm{BC}_{1}^{\mathrm{K} 1}$ e $\mathrm{B}_{2}{ }^{\mathrm{K} 1}$ deformados por K2 e verificar a homogeneidade da sua deformacão.

A figura 15 apresenta um diagrama ir do conjunto de foliações $\mathrm{K}_{1}$ e Ka medidos na Região de Abadiânia; neste diagrama, o eixo médio da deformação promovida por $K .2$ é concordante com os eixos de Tanks e de boudin. A figura 16

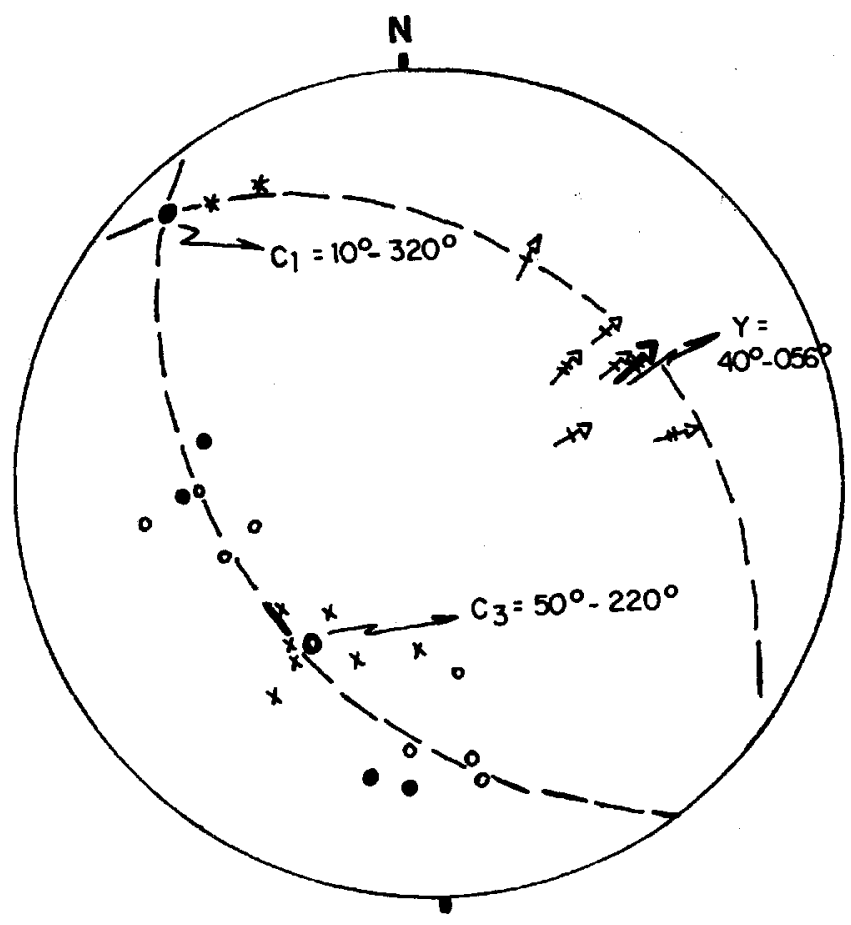

Figura 13 - Diagrama $\pi$ e $\beta$ que apresenta as relaçōes de $K_{1}$ com os planos conjugados de kink normal e reverso no Segmento EF1. Eixo de kink<t-normal e<t-reverso. Planos conjugados de kink 0 normal e $\bullet$ reverso. Demais stmbolos como os da figura 5

Figure $13-\pi$ and $\beta$ diagram to present the relationships betw cen the $K_{1}$ surface and the conjugated planes of the aormal and reverse kinks in the EF1 Segment. \& -normal and < 4 -reverse kink axis. normal and $\bullet$ reverse kink planes. The others symbols are as figure 5

Figura 14 - Diagramas $\pi$ - $\beta$ da deformação de $S_{1}$ e de $S_{2}$ por $K_{1}$. A. Segmento EF1, no qual estão apresentadas as superficies de kink medidas isoladamente; B. Segmento EF2 e sua relação com $K_{2}$ e com as superficies de kink; C. Segmento EF3 e sua relação com $K_{2}$, designa as superficies conjugadas de kink. Demais símbolos como os da figura 5

Figure $14-\pi$ and $\beta$ diagrams to show the deformation of $S j$ and $S_{2}$ by $K_{1}$. A. EF1 Segment, where are also presented the kink planes isolatedly measured; B. EF2 Segment and its relationship with $\mathrm{K}_{2}$ and with kink planes; C. EF3 Segment and its relationship with $\mathrm{K}_{2}$ designate the conjugated kink planes. The others symbols are as figure 5
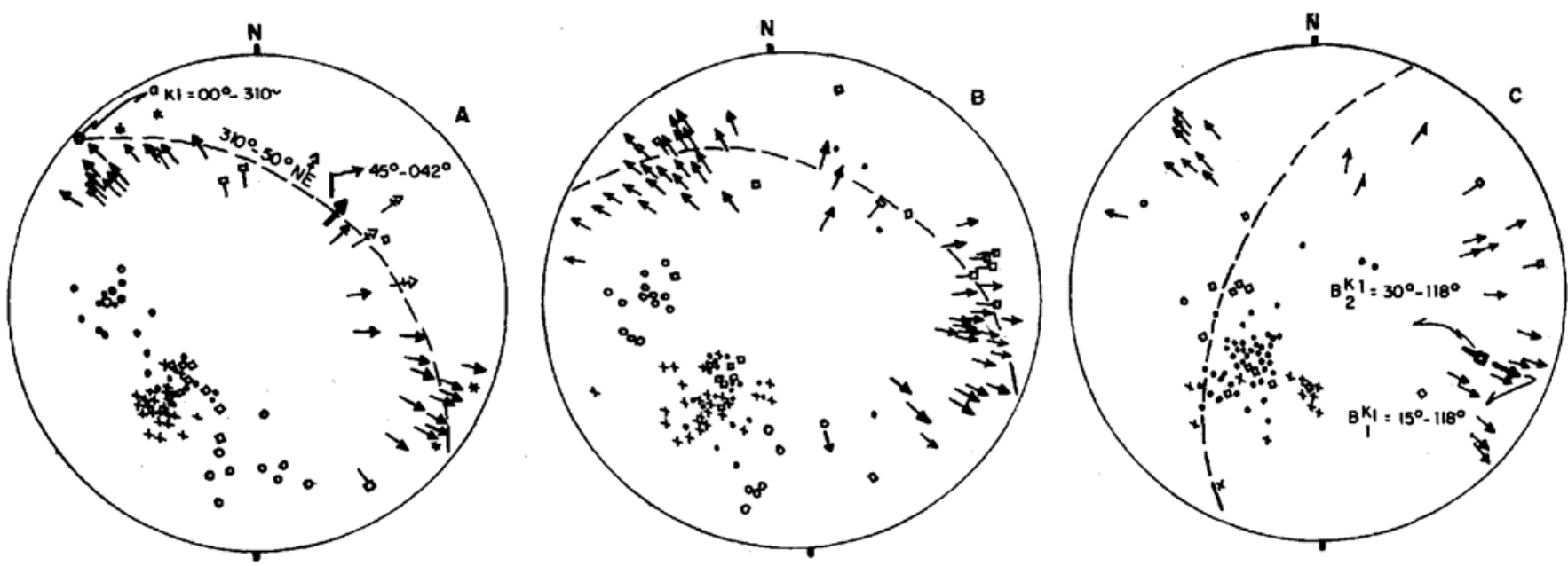


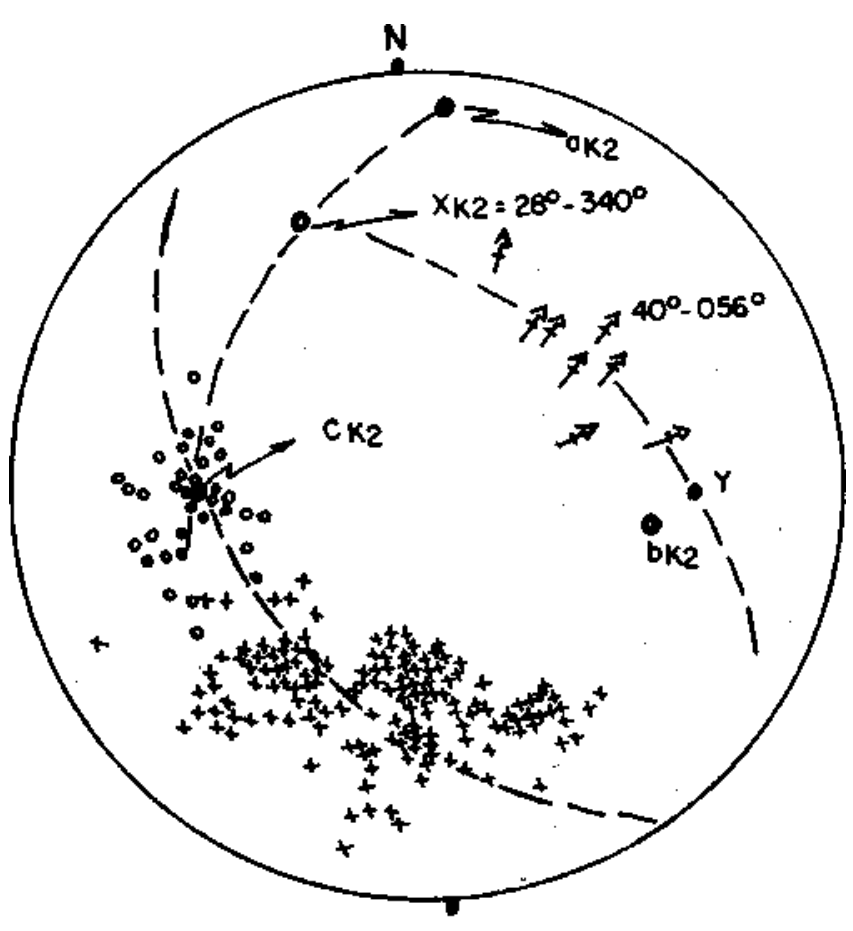

Figura 15 - Diagrama $\pi$ do conjunto das foliações $K_{1}$ e $K_{2}$ medidas na região de Abadiânia, o qual determina a natureza da inflexão de $K_{1}$ por $K_{2}$ e relaciona esta inflexão com os eixos de kink e de boudins. Símbolos iguais àqueles da figura 5 Figure $15-\pi$ diagram of the $K_{1}$ and $K_{2}$ foliations measured in the Abadiânia region, which determine the nature of the inflection of $\mathrm{K}_{1}$ by $\mathrm{K}_{2}$ and relate this inflection to the kink and boudin axis. The symbols are the same as figure 5

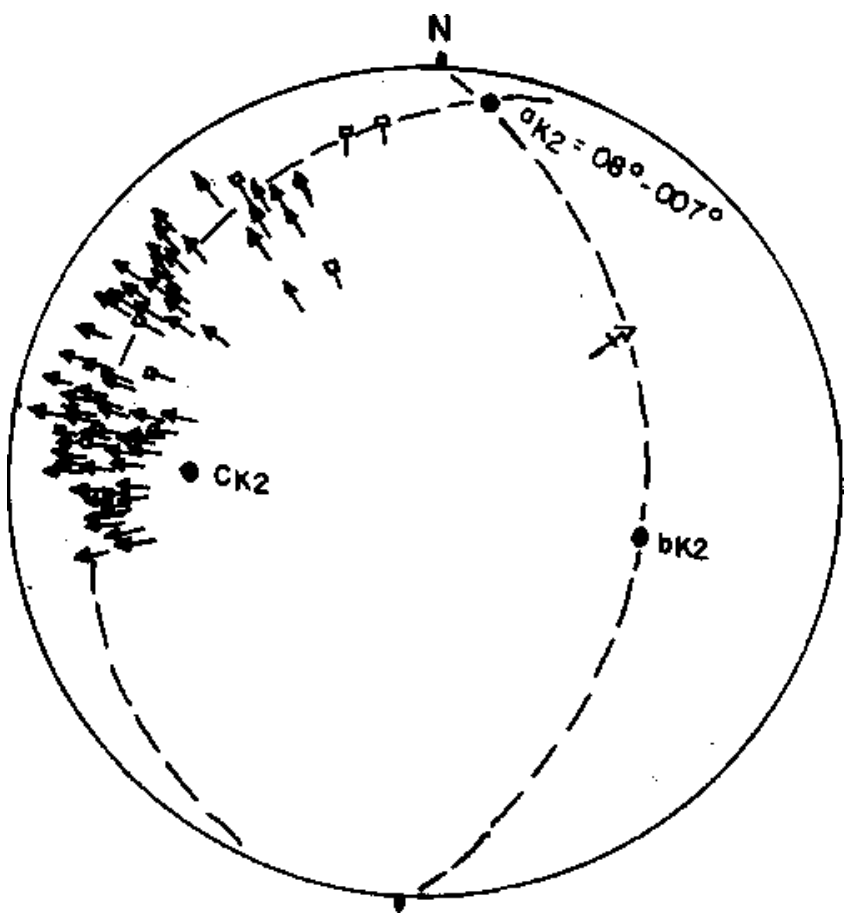

Figura 16 - Diagrama $\mathrm{P}$ para os eixos $B_{1}{ }^{K 1}$ e $B_{2}{ }^{K 2}$ dos vários segmentos individualizados na região de Abadiânia, o qual foi utilizado para estabelecer a natureza da inflexão de $K_{1}$ por $K_{2}$. Símbolos como na figura 5

Figure 16 - $\mathrm{P}$ diagram of the $\mathrm{B}_{1}{ }^{\mathrm{k} 1}$ and $\mathrm{B}_{2}{ }^{\mathrm{k} 1}$ axis measured in all segments in the Abadiânia region, which was used to stablish the nature of the $\mathrm{K}$ ! inflection. The symbols are the same as figure 5 apresenta a dispersão dos eixos $\mathrm{B}^{\wedge 1} \mathrm{e} \mathrm{BjS}^{1}$ medidos em toda a área estudada; esta dispersão se faz sobre um grande círculo, com a mesma orientação geral daquele onde ocorre a dispersão de $\mathrm{B}_{1}^{2}$ nos diversos segmentos já estudados e indica, também, um mecanismo de cisalhamento simples para a deformação causada por K2. Deste modo, a análise estrutural mostra que a direção $\mathrm{a}_{k 2}$ de cisalhamento tem atitude 08 - 007.

A figura 17 apresenta uma comparação entre o conjunto da direções de cisalhamento determinadas até aqui e as principais direções de deformação determinadas a partir do conjunto kink-boudins. Esta comparação mostra, com coerência, que há uma relação entre aquelas superfícies na medida em que as direções de cisalhamento estão contidas lias superfícies conjugadas médias do conjunto kink-boudins *

Outro método utilizado para verificar a natureza das superfícies regionais $K_{1}$ e $K_{2}$ consiste numa quantificação da intensidade de cisalhamento $(\gamma)$ desenvolvida por Ka. Para isso, tomou-se o modelo simplificado da figura 18, algumas relações matemáticas fornecidas por Ramsay (1980) e, medido $\mathrm{o}$ ângulo médio entre $\mathrm{K}_{1}$ inicial e final no plano $\mathrm{a}_{\mathrm{k} 2}-\mathrm{c}_{\mathrm{k} 2}$, obtém-se a expressão associada à figura 18.

Estes resultados são apresentados na figura $15 \mathrm{e}$, se comparados às figuras 13 e 17, mostram uma concordância muito boa tanto com relação à localização dos semi-eixos de máxima $\left(\mathrm{e}_{1}\right.$ e de mínima $\left(\mathrm{e}_{3}\right)$ elongação, quanto com relação à diferença angular entre as superfícies de cisalhamento determinadas acima $\left(67^{\circ} 30^{\prime}\right)$ e aquela entre os planos de kink $\left(65^{\circ}-70^{\circ}\right)$.

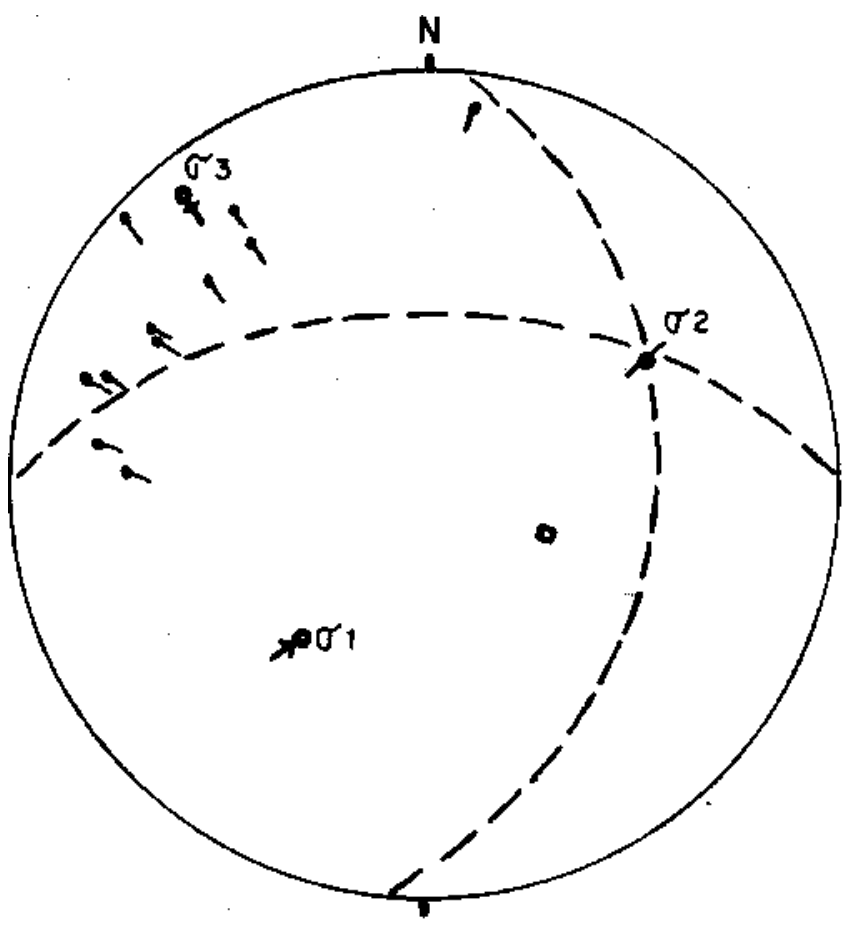

$a_{k 1}-a_{k 2} O-c_{2}-O-\left(e_{1}\right)$ max. elong. $O+\left(e_{y}\right)$ min. elong. $O \leftarrow$

Figura 17 - Diagrama $\beta$ das direções de cisalhamento $a_{K 1} e$ $\mathrm{a}_{\mathrm{k} 2}$ obtidas no tratamento dos dados estruturais dos vários segmentos. Observar as relações destas direções de cisalhamento com as superficies conjugadas médias do conjunto kink/boudin , com as direções de máxima e de mínima elongação determinadas a partir daquelas estruturas Figure 17 - $\beta$ diagram of the $a_{k 1}$ and $a_{k 2}$ shear direction obtained in the treatment of the structural data of all segments. Observe the relationship $b c \&$ een these shear directions, the mean kink/boudin conjugated planes and the directions of maximum and minimum elongation determined from that structures 


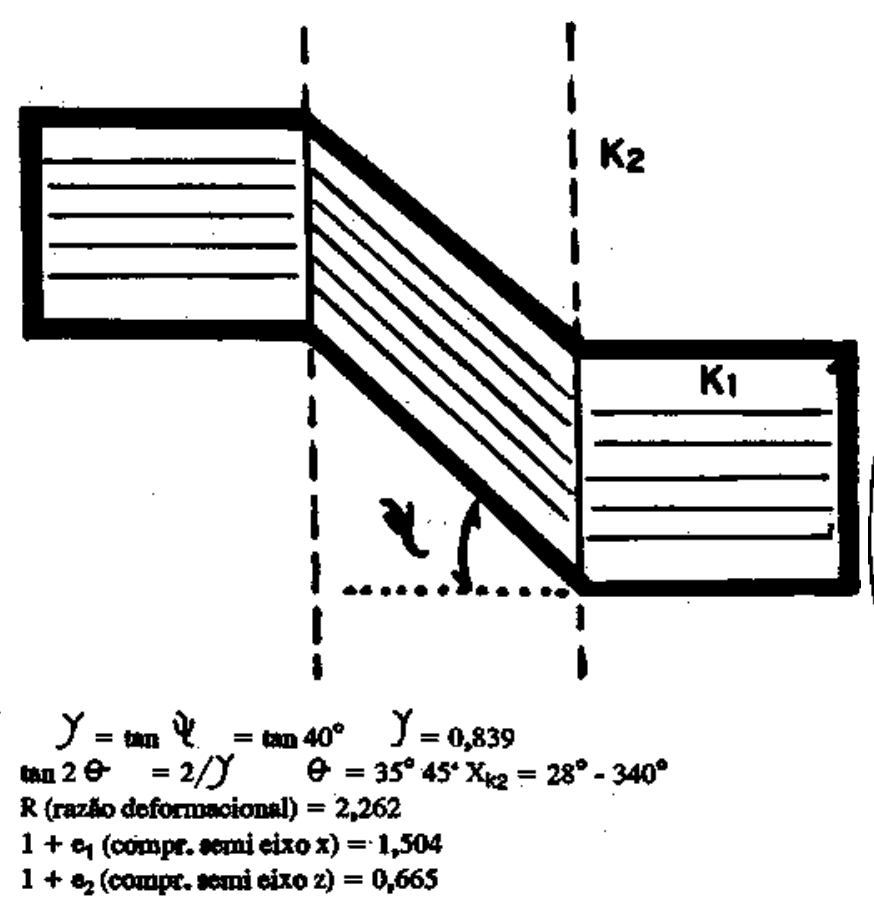

Figura 18 - Modelo simplificado da inflexão de $K_{1}$ por $K_{2}$ para o cálculo da intensidade de cisalhamento envolvida na deformação por $K_{2}$

Figure 18 - Simplified model of the $\mathrm{K}_{1}$ inflection used to calculate the shear strain intensity involved in the $\mathrm{K}_{2}$ deformation

A inserção destes resultados sobre uma rede estereográfica (Fig. 19) define os campos do elipsóide geral de deformação onde há elongação e encurtamento e pode ser comparado àquele determinado a partir do conjunto kink-boudin (Fig. 17).

Assim, pode-se interpretar $\mathrm{K}_{1}$, e $\mathrm{K}_{2}$ como superfícies conjugadas de cisalhamento direciona! de natureza dúctil que foram desenvolvidas na fase-deformacional $\mathrm{D}_{3}$. $\mathrm{O}$ sentido do deslocamento direciona! da superfície $\mathrm{K}_{2}$ pode ser facilmente avaliado a partir da inflexão de $\mathrm{K}_{1}$ : deslocamento dextrógiro. Já a avaliação do sentido de deslocamento da superfície $\mathrm{K}_{1}$ é mais difícil, porque o marcador geológico a partir do qual o sentido de deslocamento poderia ser avaliado $\left(\mathrm{S}_{1} / / \mathrm{S}_{2}\right)$ tem uma pequena angularidade com a direção $\mathrm{a}_{\mathrm{k} 1}$ de cisalhamento (ver: Estrutura das fases $\mathrm{D}_{1}$ e $\mathrm{D}_{2}$ ). No entanto, o posicionamento das superfícies de descontinuidade em relação às dobras $\mathrm{F}_{\mathrm{k} 1}$, que podem ser encaradas como drags, indica um deslocamento levógiro e o caimento da direção $\mathrm{a}_{\mathrm{k} 1}$ de cisalhamento um pouco menor do que o mergulho das superfícies $S_{1}$ $/ / \mathrm{S}_{2}$.

$\mathrm{O}$ fato de $\mathrm{K}_{2}$ ter um desenvolvimento mais tardio do que $K$ ! faz com que a foliação $K_{1}$ e a direção $a_{k 1}$ de cisalhamento sejam infletidas para a orientação do plano de máximo encurtamento $\left(\mathrm{e}_{1}-\mathrm{e}_{2}\right)$ do elipsóide geral de deformação (Ramsay 1980) e permite esclarecer melhor as estruturas descritas no Segmento EF1. A inflexão de $\mathrm{K}_{1}$ para uma posição perpendicular à direção de máximo encurtamento, em conseqüência do incremento de $\mathrm{K}_{2}$, também favorece o generalizado desenvolvimento da xistosidade $K_{1}$ não só no Segmento $E F 1$, mas também nos segmentos adjacentes que possuam a superfície $\mathrm{K}$, infletida. As estruturas do tipo mesolitons de crenulação e boudins com pequeno contraste de ductilidade são conseqüência direta da transposição de $\mathrm{K}_{1}$ sobre as tramas deformacionais anteriores. Por outro lado, os boudins onde o contraste de ductilidade inexiste são estabelecidos diretamente sobre a trama gerada por $\mathrm{K}_{1}$; este último tipo de estrutura é

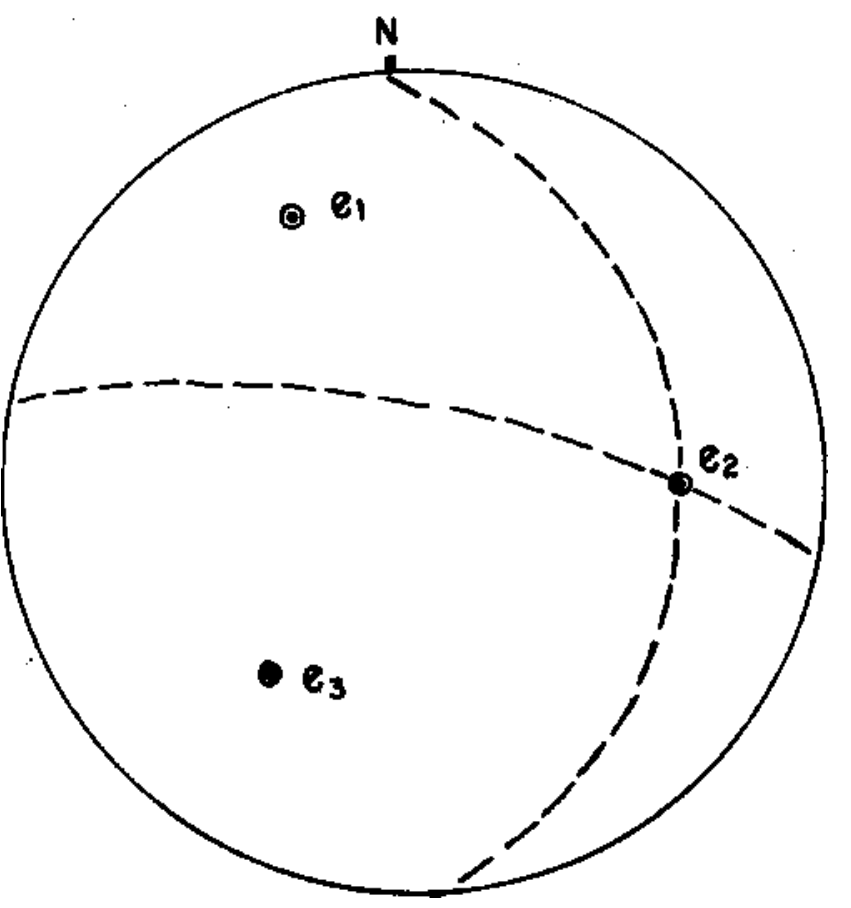

Figura 19 - Representação estereográfica (hemisfério inferior de rede igual-área) do elipsóide de deformação obtido por meio do cálculo da intensidade de cisalhamento de $K_{2}$ sobre $K_{1}$, a qual fornece os campos de elongação máxima e mínima Figure 19 - Stenographic representation (lower hemisphere of the equal-area net) of the total strain elipsóide obtained from the calculation of $\mathrm{K}_{2}$ shear strain intensity, $\mathrm{w}$ ich shov $s$ the maximum and minimum elongation fields

descrita por Cobbold et al. (1971) como "boudinagem interna", ocorre em íntima associação com kinks normais e indica que os esforços geradores da xistosidade $\mathrm{K}_{1}$ tiveram continuidade para além do limite de transposição total.

O kink reverso, ao contrário, marca que esforços compressivos atuaram ao longo da xistosidade $K_{1}$. A sua pequena ocorrência, se comparada com os kinks normais, pode indicar uma fraca reorientação dos esforços como resultado de recomposição elástica na fase final do evento deformacional Da. Esta interpretação é coerente com a estrutura da figura 12, na qual os dois tipos de kink estão associados.

A interpretação do diagrama de frequência de fraturas apresentado na figura 20 se torna facilitada após a discussão e caracterização da natureza da deformação. Dois máximos importantes são ressaltados na figura 20: a. o primeiro corresponde a fraturas aproximadamente N-S, que representam a superfície $\mathrm{K}_{2}$ e que causam a inflexão das estruturas geradas por $\mathrm{K}_{1}$ b. o segundo são fraturas distensivas de orientação $\mathrm{NE}$ e que representam o plano bissetor obtuso das duas superfícies conjugadas de cisalhamento.

\section{ANÁLISE INTEGRATIVA DAS FASES $D_{1} D_{2} E$}

DS $\mathrm{O}$ exame detalhado dos procedimentos de análise de Ramsay (1967) permite mostrar que a tendência de B!pe de $\mathrm{B}_{2}{ }^{\mathrm{K} 1}$ estarem próximas da direção $\mathrm{a}_{\mathrm{k} 1}$ de cisalhamento é conseqüência dessa direção de cisalhamento estar localizada sobre, ou muito próxima das superfícies $\mathrm{S}_{1} / / \mathrm{S}_{2}$. Neste caso, a dispersão dos eixos B? deve necessariamente se fazer sobre a superfície $\mathrm{S}_{1} / / \mathrm{S}_{2}$, qualquer que seja a orientação original de $\mathrm{B}$ ? Desse modo, as superfícies de melhor ajuste para a dispersão de $\mathrm{B}_{1}{ }^{2}$, obtidas para os diversos segmentos, têm uma orienta- 


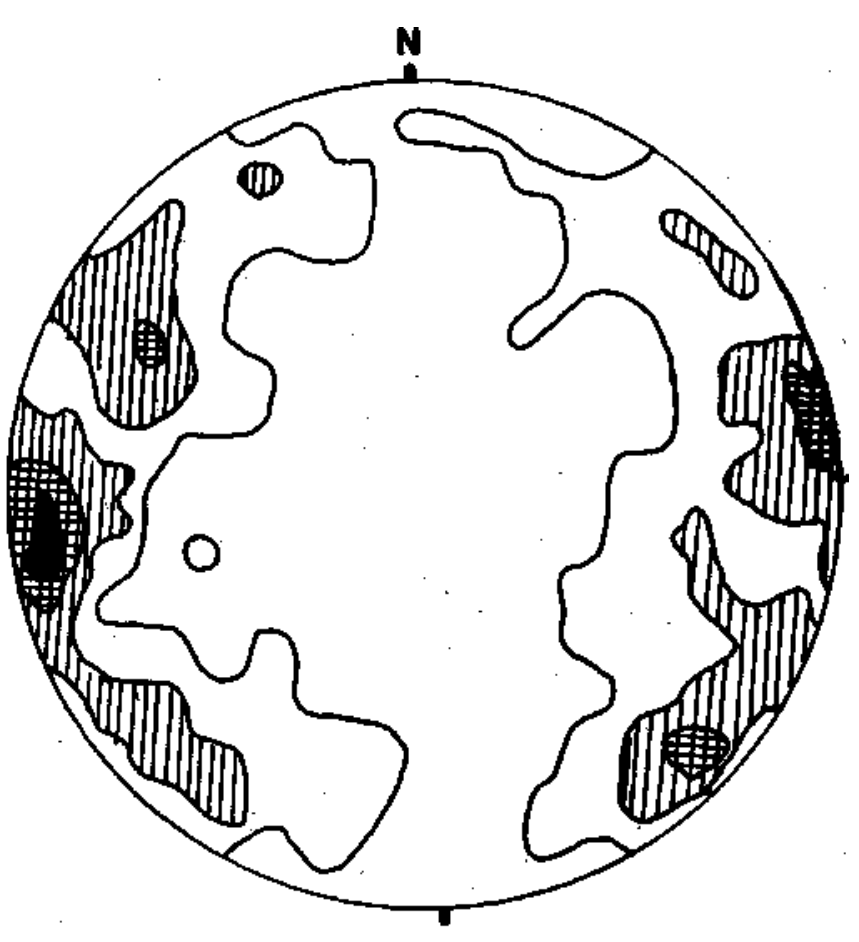

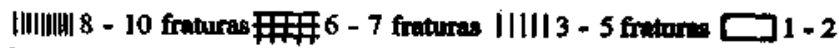
fraturas

Figura 20 - Diagrana de freqïência de froturas. Total: 136 fraturas

Figure 20 - Diagram of fracture fintuence. Total: 136 frecturea

cão média em $200-25 \mathrm{NW}$ e representam a orientação original de $\mathrm{S}_{2}$.

A atitude média $200-25 \mathrm{~N} \mathrm{~W}$ de $\mathrm{S}_{2}$ e a sua caracterização como superfície de achatamento (granadas com estrutura interna $\mathrm{S}_{\mathrm{i}} / \mathrm{S}_{2 \mathrm{e}}$ ) definem, para esta fase, dobras recumbentes $\mathrm{F}_{2}$ com vergência ESE. As dobras $F_{2}$ estão estruturadas sobre a pseudo-estratigrafia resultante de um intenso processo de milonitização regional $\left(\mathrm{D}_{1}\right)$, que afeta todos os litotipos da área de modo a resultar contatos exclusivamente tectônicos por meio de $\mathrm{S}_{1}$

A paralelização de $S_{1}$ e de $\mathrm{S}_{2}$ é indicada pela formação da macroestrutura bandada nos granada-mica-quartzo xistos. Porém, a existência de crenulações tipo microdobras $\mathrm{F}_{2}$ permite avaliar a relação angular entre $S_{1}$ e $S_{2}$, conforme esquematizado na figura 4 , e, desta forma, fazer uma correlação estratigráfica entre os diversos segmentos para definir a estruturação de $\mathrm{D}_{2}$ e de $\mathrm{D}_{1}$. Por meio deste procedimento, foi possível estabelecer a pseudo-estratigrafia envolvida no dobramento $\mathrm{F}_{2}$, representada esquematicamente na figura 21 .

Duas observações importantes resultam, ainda, da análise dos diagramas ir e (3 construídos. A primeira, apresentada nas figuras 5 e $8 \mathrm{D}$, diz respeito a medidas em mesoestrutura da fase deformacional $\mathrm{D}_{2}$ : verifica-se que a dispersão espacial de $\mathrm{S}_{\mathrm{t}}$ em torno de $\mathrm{B}_{1}{ }^{2}$ se faz ao longo da mesma superfície que a dispersão de $\mathrm{S}_{1}$, e $\mathrm{S}_{2}$ em torno de $\mathrm{B}_{1}{ }^{\mathrm{K}} \mathrm{e}$ de $\mathrm{B}_{2}{ }^{\mathrm{K1}} \mathrm{A}$ segunda, mais claramente verificada nas figuras $6 \mathrm{D}, 6 \mathrm{~F}$ e $6 \mathrm{G}$, mostra que há uma dispersão dos eixos $\mathrm{B}_{1}^{\mathrm{K} 1} \mathrm{e}$ que esta dispersão se faz ao longo da mesma superfície onde dispersam $\mathrm{B}_{1}^{2}$ : seria de se esperar que esta dispersão ocorresse ao longo da superfície $K_{1}$, já que $\mathrm{S}$, foi previamente deformada em $\mathrm{D}_{2}$ (Turner \& Weiss 1963). Embora a dispersão de $\mathrm{B}_{1}^{\mathrm{K1}}$ seja mais restrita do que aquela de $\mathrm{Bf}$ e possa estar relacionada à superposição de $\mathrm{K}_{2}$, ambos os aspectos parecem indicar uma pequena angularidade inicial entre $S_{1}$ e $S_{2}$ e uma coaxialidade das deformações causadas

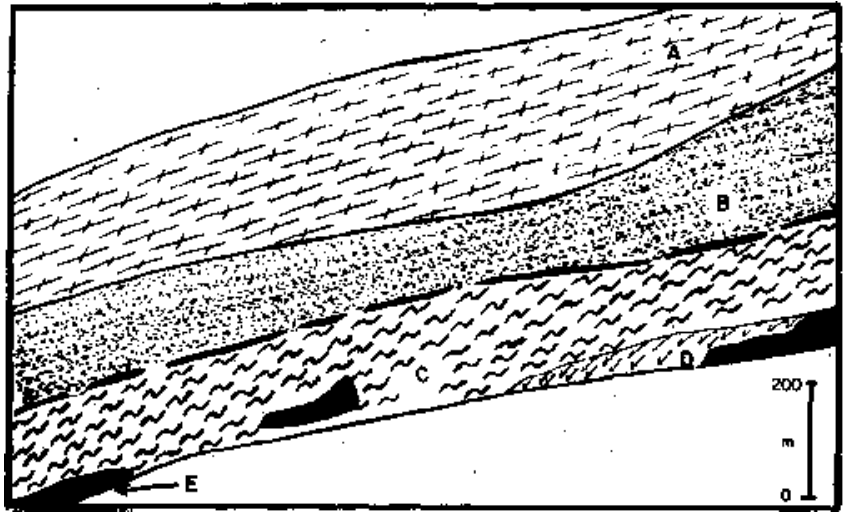

Figura 21 - Pseudo-estratigrafia resultante da deformação müoniüca da fase $\mathrm{D}_{1}$ Legenda: A. gnaisse/xisto porftroclástico; B. moscovita quartzito con nível de grafita-moscovitaquartzo xisto no contato transicional com $\mathbf{C}$. granada-micaquartzo xisto; D. corpos máficos; E. corpos ultramáficos Figure 21 - Pseudo-stratigraphy resulting from milonitic deformation of $\mathrm{D}_{1}$ phase. Legend: A. porphyroclastic gneiss/schist; $\mathrm{B}$. muscovite quartzite with the transitional grafite-muscovite-quartz schist to the $\mathrm{C}$. garnet-mica-quartz schist; D. mafic bodies; E. ultramafic bodies

por $\mathrm{S}_{2}$ e $\mathrm{K}_{1}$, o que justifica o pequeno espectro de dispersão de $\mathrm{B}_{1}^{2}$ (Ramsay 1967).

$\mathrm{A}$ amplitude da dispersão de $\mathrm{B}_{1}{ }^{2}$ vai depender do ângulo inicial que este eixo faz com a direção $a_{\mathrm{k} 1}$ de cisalhamento, da intensidade de cisalhamento e, também, do ângulo diedro entre as superfícies $\mathrm{S}_{2}$ e $\mathrm{K}_{1}$. Uma vez que o ângulo diedro entre $\mathrm{S}_{2}$ e $\mathrm{K}_{1}$ está em torno de $40^{\circ}$ e a dispersão de $\mathrm{B}_{1}^{2}$ se faz próxima da direção $\mathrm{a}_{\mathrm{k} 1}$ de cisalhamento, pode-se levantar duas possibilidades: 1. a orientação original de $\mathrm{B}_{1}{ }^{2}$ era de alto ângulo com a direção $\mathrm{a}_{\mathrm{k} 1}$ de cisalhamento e, para se obter uma concentração de $\mathrm{B}_{1}{ }^{2}$ em torno daquela direção, a intensidade do cisalhamento foi maior do que 1,7 (ângulo entre $\mathrm{B}_{1}{ }^{2} \mathrm{i}$ $\mathrm{B}_{1}^{2} \mathrm{f}>70^{\circ}$ ), o que parece não ser o caso devido à inexistência de uma xistosidade $K_{1}$ generalizada em toda a área; 2 . o eixo $\mathrm{B}_{1}^{2}$ faz um ângulo relativamente pequeno com a direção $\mathrm{a}_{\mathrm{k} 1}$ de cisalhamento e qualquer tentativa de se quantificar a intensidade de cisalhamento resulta em valores mínimos de aplicação duvidosa.

A segunda possibilidade está de acordo com a mesoestrutura identificada em afloramento do Rio Corumbá (Fig.8) onde $\mathrm{B}_{1}^{2}(22-300)$ está numa posição que, no mínimo, pode ser caracterizada como um "obstáculo" à continuidade da deformação gerada pela superfície $\mathrm{K}_{1}$. Uma comparação entre as figuras 5,17 e 19 mostra que a localização do semi-eixo de mínima elongação do elipsóide geral de deformação fo $=45$ 210) é aproximadamente perpendicular a $\mathrm{B}_{1}{ }^{2}(22-300)$. Estas relações apontam para uma pequena angularidade entre $\mathrm{B}_{1}{ }^{2}$ e $\mathrm{a}_{\mathrm{k} 1}$, como é sugerido pela análise dos diagramas ir e (3; além disso, sugerem uma relação cinemática entre as fases de deformação $\mathrm{D}_{2}$ e $\mathrm{D}_{3}$, que será analisada na próxima sessão.

Assim, alcançado esse ponto de análise, parece importante retomar a discussão realizada no início da sessão "Fase Deformacional $\mathrm{D}_{3}{ }^{\prime}$, na qual se caracterizou o mecanismo de deformação que gerou a superfície de deformação $K_{1}$; naquele momento, foram analisadas algumas razões para a pequena dispersão dos eixos $\mathrm{B}_{1}{ }^{2}$ ao longo da superfície $200-25 \mathrm{NW}$. Neste momento, com a indicação de uma pequena angularidade entre $\mathrm{B}_{1}^{2}, \mathrm{a}_{\mathrm{k} 1}$ e $\mathrm{B}^{\mathrm{K} 1}$, está-se diante de uma deformação quase homoaxial entre as dobras $\mathrm{F}_{2}$ e $\mathrm{F}_{\mathrm{k} 1}$, e diante de uma razão adicional para aquela pequena dispersão. Contudo, a observação das figuras 5 e 6 mostra que a dispersão dos eixos $\mathrm{B}^{\wedge}$, embora minimizada pela proximidade dos eixos deformacionais, ainda não pode ser ajustada em um cone com cen- 
tro em $\mathbf{B}^{\mathbf{k} 1}$, mas, sim, num plano de retomada. Portanto, a interpretação de $\mathrm{K}_{1}$ como superfície de cisalhamento é mantida e reforçada dentro do quadro geral de deformação da fase $\mathrm{D}_{3}$.

A partir desta definição das condições de deformação da fase $\mathrm{D}_{3}$, pode-se observar que a orientação inicial da superficie $\mathrm{S}_{2}$ está localizada no campo de encurtamento do elipsóide geral de deformação $\mathrm{D}_{3}$ (Figs. 17 e 19). Esta condição, portanto, dá início à formação das dobras tipo kink de expressão regional que foram esquematicamente representadas na figura 22. De um outro modo, se forem comparadas as figuras 5 e 6 com as figuras 14 e 16, observar-se-á que os flancos inversos infletem progressivamente para o campo de alongamento e, portanto, sofrem deslocamentos direciqnais ao longo das superfícies de descontinuidade descritas. Os diferentes esforços aplicados sobre as dobras $\mathrm{F}_{\mathrm{k} 1}$ vão, então, resultar na diferença do padrão de crenulação observado: microdobras no flanco normal e na charneira e microcisalha no flanco inverso.

Outro aspecto que deve obrigatoriamente ser observado diz respeito à indicação de uma orientação $\mathrm{N} \mathrm{W}$ para o eixo $\mathrm{B}^{2}$. Como todo o processo deformacional ocorreu dentro das mesmas condições gerais de metamorfismo e como esta associação petrotectônica representa depósitos de calha de subducção (Strieder \& Nilson, subm), pode-se esperar uma estreita relação cinemática e temporal entre as fases $D_{1}$ e $D_{2}$ Desse modo, a pequena angularidade entre $S_{1}$, e $S_{2}$ pode ser preferencialmente traduzida numa diferença de mergulho, mas não numa diferença considerável de direção, pois isto mudaria significativamente os padrões de subducção. Assim, seria de se esperar que o eixo $\mathrm{B}^{2}$ tivesse uma direção próxima daquela da superfície $S_{2}$ e não uma direção quase ortogonal, que, na verdade, seria a direção de transporte das dobras recumbentes F2.
A avaliação precisa do significado desta obliqüidade necessita, ainda, de alguns trabalhos regionais e depende de uma boa compreensão dos padrões deformacionais desenvolvidos em zonas de convergência de placas.

Na seção seguinte, é apresentada uma discussão sobre os padrões deformacionais desenvolvididos na região de Abadiânia por meio de uma correlação com os padrões já conhecidos.

DISCUSSÃO Para procurar compreender as condições gerais em que as estruturas caracterizadas foram formadas, deve-se considerar duas possibilidades quanto à cinemática da deformação na região de Abadiânia: a. $\mathrm{B}^{2}$ está servindo, casualmente, de obstáculo à deformação promovida por uma reorientação de esforços dentro de um mesmo ciclo tectonotérmico, ou b. o desenvolvimento de $\mathrm{B}^{2}$ torna-se parte ativa, como causador, na instalação das superfícies conjugadas $\mathrm{K}_{1}$ $\mathrm{K}_{2}$ de cisalhamento direcional.

O tipo de associação/estruturação tectônica comumente descrito para zonas de cavalgamento (Sanderson 1982) envolve o transporte diferencial das nappes pela adição de uma componente de cisalhamento tipo wrench, de modo a originar dobras "em bainha" de larga escala. Os modelos deformacionais analisados para esses terrenos (Sanderson 1979 e 1982, Coward \& Potts 1983, Rattey \& Sanderson 1982) indicam uma diminuição no mergulho do planoaxial, do ângulo interlimbos e da assimetria dos dobramentos recumbentes com a proximidade da superfície basal de cavalgamento; ocorre, também, uma diminuição da assimetria'dos dobramentos recumbentes basais em direção às zonas onde o cisalhamento tipo wrench tem expressão dominante (Fig. 23A).

Nesse tipo de estruturação tectônica, a história tectonodeformacional registrada na região de Abadiânia torna-se

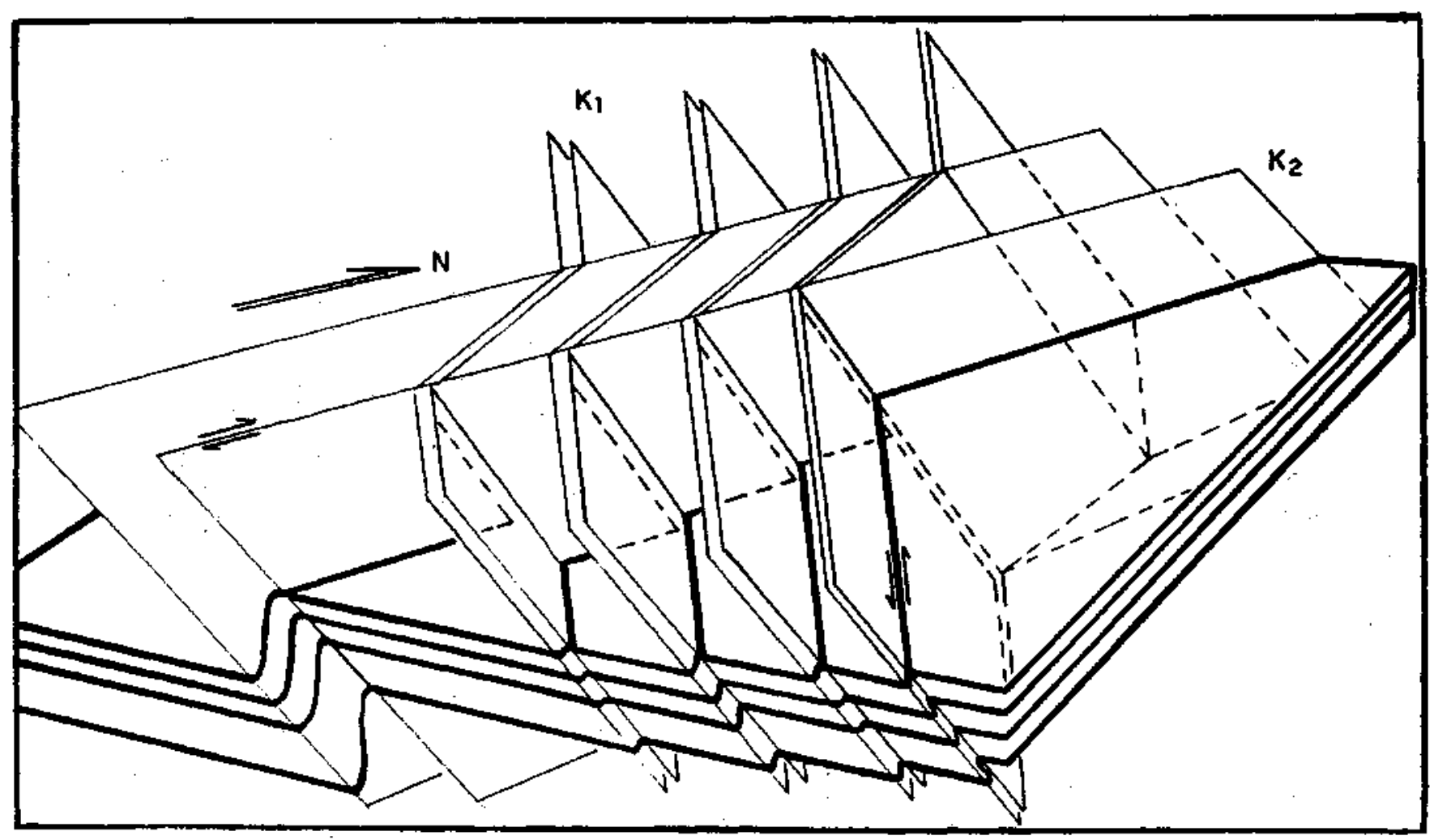

Figura 22 - Representação esquemática tridimensional da articulação das superficies conjugadas K1 eK2 da deformação produzida sobre as superficies $\mathrm{S}_{1} / / \mathrm{S}_{2}$ : dobras assimétricas tipo kink de pequena amplitude Figure 22 - Tridimensional sketch presenting the articulation of the $\mathrm{K}_{1}$ and $\mathrm{K}_{2}$ conjugated surfaces and the deformation promoted on S-)// $\mathrm{S}_{2}$ surfaces: assimetric kink-type folds of small amplitude 


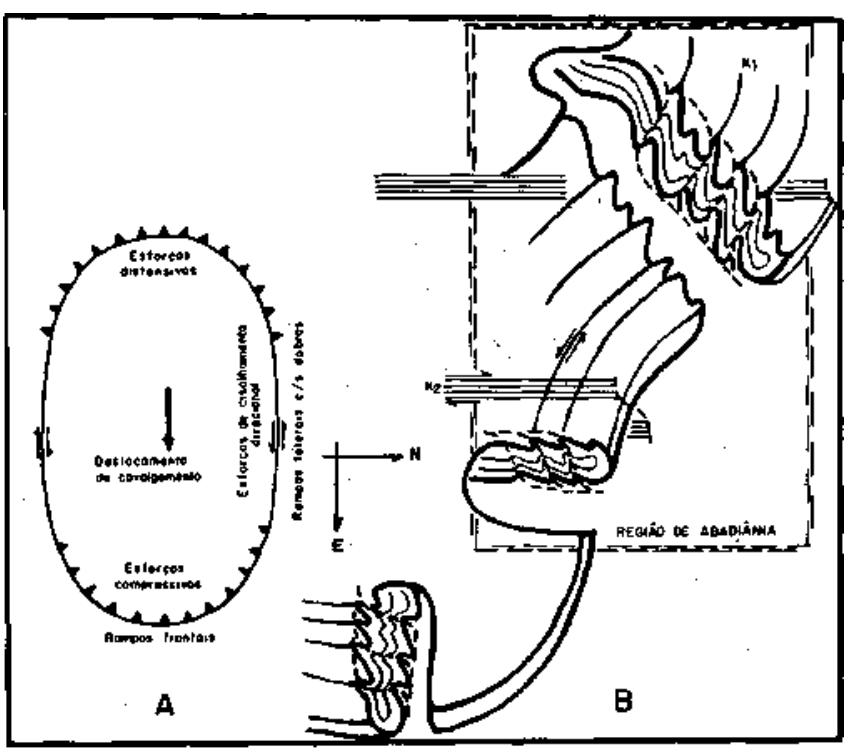

Figura 23 - A. Modelo esquemático da distribuição dos esforços e da deformação nas zonas que envolvem processos de cavalgamento e transporte diferencial de lâminas de thrust. $\mathbf{B}$. Representação tridimensional esquemática da deformação interna da lâmina de cavalgamento onde a região de Abadiânia está situada. As rampas laterais $\left(K_{1}\right)$ e a superficie $K_{2}$ sugerem, para a região, uma estrutura interna do tipo foreland dipping duplexes

Figure 23 - A. Sketched model for the distribution of stress and strain in zones that where subjected to thrust processes with diferential movement of the thrust sheets. B. Tridimensional sketch presenting the internal deformation of the thrust sheet where Abadiânia region is located. The lateral ramps $\left(\mathrm{K}_{1}\right)$ and the $\mathrm{K}_{2}$ surfaces suggest a foreland dipping duplexes structure for this region

mais clara, e a superposição das diversas superfícies de deformação dentro de um único ciclo tectono-térmico pode indicar que as variações espaciais na taxa de deformação desenvolveram uma cronologia local para a história deformacional (Ridley 1986). Os modelos introduzidos acima (Fig. 23A) tratam basicamente de analisar, dentro da lâmina de cavalgamento, a variação dos esforços que levam à formação de rampas frontais ou laterais com mergulho voltado contrário ao seu senso de deslocamento (hinterland dipping: Boyer \& Elliott 1982).

A limitação da área mapeada não permite a identificação das superfícies superior e inferior da lâmina de cavalgamento (roof and floor thrusts\}, tampouco uma investigação mais regionalizada do comportamento e do caráter espacial das superfícies conjugadas $\mathrm{K}_{1}-\mathrm{K}_{2}$; porém, considerada a geometria e o posicionamento de $\mathrm{K}_{1}$, pode-se interpretá-la como rampas laterais cujo mergulho está segundo o senso de deslocamento e expansão de grandes nappes. Assim, se $\mathrm{K}_{1}$ e $\mathrm{K}_{2}$ são rampas internas de uma lâmina de cavalgamento, pode-se caracterizar, para a região, uma estrutura do tipo foreland dipping $d u$ plexes (Boyer \& Elliott 1982), que, no momento, fica colocada em termos de sugestão. O caráter de rampas internas de uma lâmina de cavalgamento é fortemente sugerido pelo formato sigmoidal que adquirem as superfícies conjugadas $K_{l}-K_{2}$ (Fig. 8B), pois as porções de baixo mergulho tendem ao paralelismo com as superfícies de cavalgamento superior e inferior. De outro modo, a obliqüidade entre as direções de $\mathrm{B}^{2}$ e de $S_{2}$ pode sugerir que as dobras recumbentes desta região tenham uma geometria "em bainha" de larga escala e que o seu desenvolvimento ocorreu ligado ao processo de milonitização regional $\left(\mathrm{D}_{1}\right.$, como é normalmente verificado em zonas de convergência crustal.
A partir destas características gerais, a estrutura geológica presente junto ao paralelo $16^{\circ} \mathrm{S}$, denominada Inflexão dos $\mathrm{Pi}$ rineus, está sendo entendida como o resultado do deslocamento diferencial de uma grande nappe $\mathrm{F}_{2}$. Este deslocamento diferencial foi conduzido pelas superfícies direcionais $F_{k 1}$ (rampas laterais), que agregam a componente tipo wrench, frequentemente caracterizada nessas regiões. A figura 23B tenta ilustrar o condicionamento estrutural e tectônico da região de Abadiânia, de acordo com as características discutidas acima.

A ausência de dados nesta linha de pesquisa está sendo gradativamente preenchida pela continuidade dos trabalhos em área mais a Sul (Santa Cruz de Goiás), onde as primeiras observações indicam a presença de importantes superfícies de deslocamento direcional que causam inflexões semelhantes àquelas dos Pirineus, e a possibilidade de se confirmar o outro flanco da grande dobra "em bainha".

ALOJAMENTO DOS CORPOS DE ISERPENTINITO Os nove pequenos corpos de serpentinito individualizados na região de Abadiânia estão relacionados a algumas das superfícies de descontinuidade (Fig. 3). Isto não significa, contudo, que o seu alojamento tenha ocorrido durante o desenvolvimento de tais superfícies, pois, em todos os corpos, foram identificadas as superfícies defonnacionais $\mathrm{S}_{1}, \mathrm{~S}_{2}, \mathrm{~K}_{1}$ e $\mathrm{K}_{2}$; significa apenas que a superfície $\mathrm{K}_{1}$, pelo seu grau de desenvolvimento na região de Abadiânia, controla a geomorfologia e, portanto, o aparecimento destes corpos na superfície.

Um mapeamento estrutural foi realizado em cada corpo de serpentinito e os elementos estruturais medidos são apresentados na forma de diagramas ir e $\mathrm{p}$ na figura 24. Em termos gerais, a deformação das superfícies $S_{1}$ e $S_{2}$ por $K_{1}$ e por $K_{2}$ nos corpos de serpentinitos é compatível com a deformação das suas encaixantes.

O corpo de serpentinito CS9, localizado a leste dos demais, é flanco inverso da antiforme $\mathrm{F}_{\mathrm{k} 1}$, está truncado pela Superfície de Descontinuidade AC 1 e tem uma dispersão das foliações $S_{1}$ e $S_{2}$ que ainda não mostra a influência da superfície $\mathrm{K}_{2}$ (Fig. 24A). Já os Corpos de Serpentinito CS4, CS6 e CS8, localizados junto à antiforme da Superfície de Descontinuidade BD1, e o Corpo de Serpentinito CS7, truncado pela Superfície de Descontinuidade BD2, têm o eixo da dispersão das foliações $S_{1}$ e $S_{2}$ infletido para NW (Fig. 24C) como conseqüência da inflexão de K,; nestes corpos, é possível identificar algumas crenulações, ou fraturas pouco espaçadas que representam $K_{2}$. A inflexão do eixo de dispersão das foliações $S_{1}$ e $\mathrm{S}_{2}$ é acentuada nos Corpos de Serpentinito CS2 e CS3, que estão respectivamente localizados nos flancos normal e invertido da antiforme adjacente à Superfície de Descontinuidade EF2 (Fig. 24E). O efeito extremo é encontrado no Corpo de Serpentinito CS 1, localizado a sul da Superfície de Descontinuidade EF1, que está quase completamente transposto pela foliação $\mathrm{K}_{1}$. A identificação de crenulações $\mathrm{K}_{2}$ justifica a dispersão de $\mathrm{K}_{1}$ e os restos de 82 segundo um eixo de atitude semelhante àquele do conjunto kink-boudin (Fig. 24D).

CONCLUSÕES A compartimentação e a análise estrutural realizadas na região de Abadiânia permitiram inicialmente verificar as condições de alojamento dos corpos de serpentinito e das rochas máficas na seqüência metassedimentar do Araxá. Assim, como o granito milonitizado, foi verificado que as rochas máficas e ultramáficas foram alojadas durante uma fase de intenso processo de milonitização regional $\left(\mathrm{D}^{\wedge}\right.$ ocorrido em zona de sutura crustal, já que este tipo de associação petrotectôniça marca depósitos de calha de subducção e é conhecida como melange ofiolítica.

Em segundo lugar, o estudo geológico-estrutural realizado mostrou que a deformação impressa na região desenvolveu-se em três sucessivas fases:

$\mathbf{D}_{1}$ - Intenso processo de milonitização regional que é rés- 


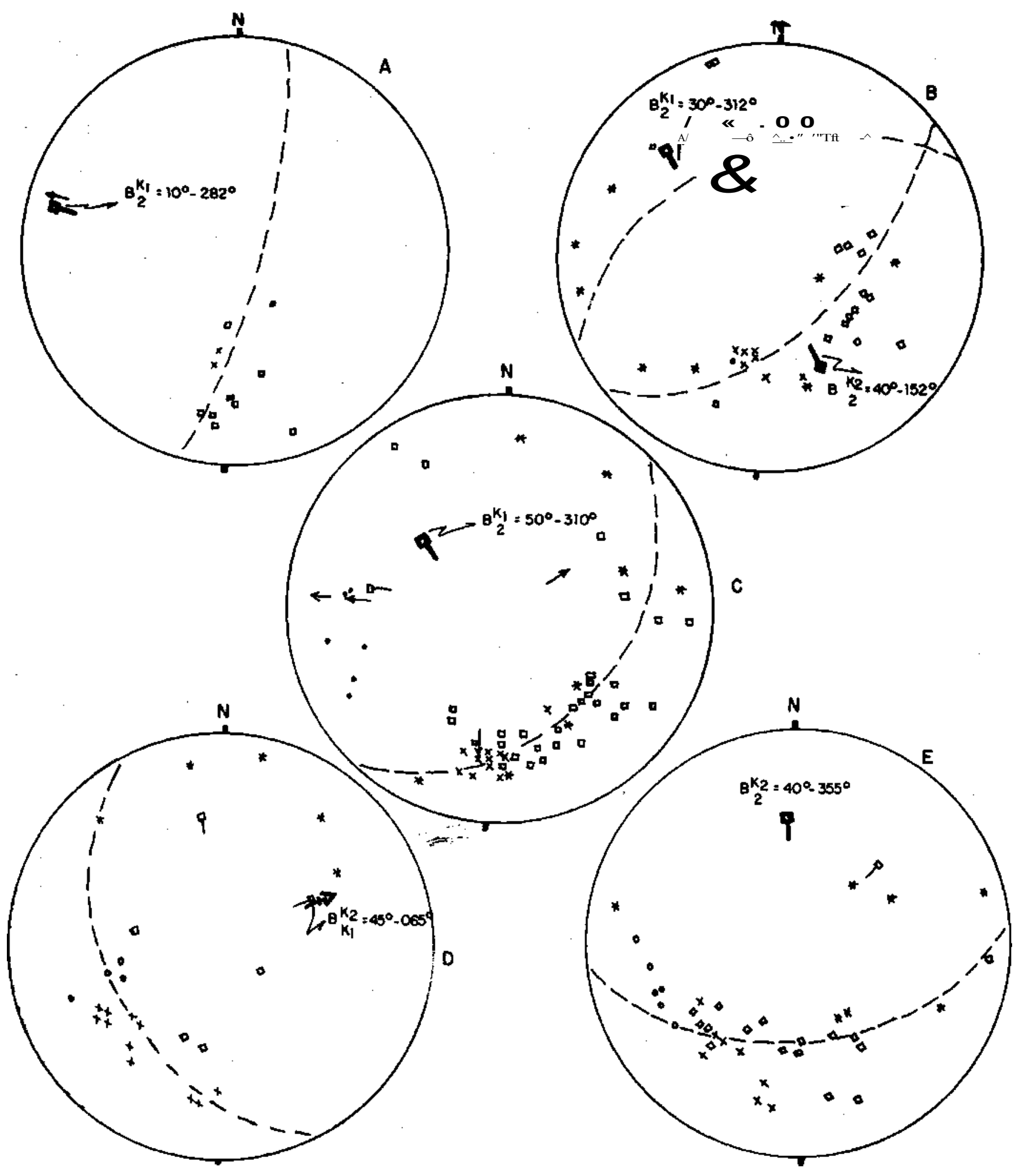

Figura 24 - Diagramas $\pi$ - $\beta$ da deformação de $S_{1}$ elou $S_{2}$ por $K_{1}$ elou $K_{2}$ nos Corpos de Serpentinito (A) CS9, (B) CS4, CS6 e CS8, (C) CS7, (D) CS1 e (E) CS2 e CS3. Símbolos como na figura 5

Figure 24 - $\Pi$ and $\beta$ diagrams of the deformation caused by $K$, and/or $\mathrm{K}_{2}$ on $S^{\wedge}$ and/or $\mathrm{S}_{2}$ of the Serpentinites Bodies (A) CS9, (B) CS4, CS6 e CS8, (C) CS7, (D) CS 1 e (E) CS2 e CS3. The symbols are as figure 5 
ponsável pela estruturação de uma pseudo-estratigrafia ordenada;

$D_{2}$ - Fase de dobramento recumbente cuja xistosidade possui uma pequena angularidade com a xistosidade/ foliação milonítica da primeira fase. $\mathrm{O}$ eixo da dobra recumbente, na região de Abadiânia, é oblíquo à direção geral de $\mathrm{S}_{2}$. Estas duas características podem sugerir que a dobra recumbente $F_{2}$ foi formada como o resultado do processo de milonitização e que possui uma geometria "em bainha" de escala regional; D3 - Fase que desenvolve duas superfícies de cisalhamento direcional $\left(\mathrm{K}_{1}\right.$ e $\left.\mathrm{K}_{2}\right)$ responsáveis por dobras com geometria kink de pequena amplitude, por superfícies de descontinuidade (falhas) e pela expressão geomorfológica dos alinhamentos atualmente observados na região. As superfícies $\mathrm{Fa}_{\mathrm{R} 1}$ estão posicionadas como rampas laterais de uma lâmina de cavalgamento de modo a introduzirem a componente de cisalhamento direcional tipo wrench, responsável pelo seu transporte diferencial e, desta forma, propiciarem o desenvolvimento de nappes com geometria "em bainha".

As relações cinemáticas entre as fases deformacionais e a observação de que uma mesma paragênese metamórfica índice recristaliza ao longo de cada superfície deformacional indicam que apenas um evento tectono-térmico foi responsável pela estruturação identificada e que, então, a região pode ser correlacionada com zonas de tectônica convergente que envolvem intensos processos de cavalgamento.

Agradecimentos O autor quer expressar os seus agradecimentos ao Professor Ariplíhio Antônio Nilson do Instituto de Geociências da Universidade de Brasília pelo auxilio nos trabalhos de campo e pelas discussões dos resultados obtidos. Também, ao colega José Affonso Brod (Instituto de Geociências da Univerdade de Brasília) e ao professor Luis A. D. Fernandes (Instituto de Geociências da Universidade Federal do Rio Grande do Sul) pelas discussões e pelas sugestões para o texto final.

\section{REFERÊNCIAS BIBLIOGRÁFICAS}

ARAÚJO F?., J.O. 1981. Contribuição à estratigrafia e tectônica da região da mega-inflexão dos Pirineus - Goiás Centro Meridional. In: SIMP. GEOL. CENTRO-OESTE, 1, Goiânia, 1981. Resumos... Goiânia, SBG. p.24-27.

ARAUJO F?., J.O. \& LEONARDOS, O.H. 1986. A esmeralda do Município de Pirenòpolis, Goiás; um exemplo de greisenização de talcoxistos. In: CONGR. BRÁS. GEOL., 34, Goiânia, 1986. Anais..., Goiânia, SBG. v. 4, p. 1835-1845.

BARNES, J.W. 1981. Basic geological mapping. Series n- 1; Hoisted Press. New York, Wiley \& Sons. 112p.

BOYER, S.E. \& ELLIOT, D. 1982 . Thrust systems. Am. Assoc. Petroleum Geol., 66 (9): 1196-1230.

COBBOLD, P.R.; COSGROVE, J.W.; SUMMERS, J.H. 1971. Development of internal structure in deformed, anisotropic rocks. Tectonophysics, 12(1):23-53.

CORDANI, U.G. \& BRITO NEVES, B.B. 1982. The geologic evolution of South America during the Archean and Early Proterozoic. Salvador, Anais...Rev. Bras. Geoc., 12 (1/3):78-88.

COSGROVE, J.W. 1976. The formation of crenulation cleavage. Jour. Geol. Soc. London., 132 (1):155-178.

COWARD, M.P. 1983. Thrust tectonics, thin skinned or thick skinned and the continuation of thrusts to deep in the crust. Jour. Struct. Geol., 5(2):in-123.

COWARD, M.P. \& POTTS, GJ. 1983. Complex strain patterns developed at the frontal and lateral tips to shear zones and thrust zones./. Struct. Geôl, 5(3/4):383-399.

DRAKE Jr, A.A. 1980. The Serra de Caldas Window, Goiás. UJS. GJS Prof. Paper, 1119 (A-B):A1-A11.

GRAY, D.R. 1977. Morphologic classification of crenulation cleavage. Jour. Geology, 85 (2):229-235.

GRAY, D.R. 1979. Geometry of crenulation-folds and their relationship to crenulation cleavage. Jour. Struct. Geol., 1 (3): $187-205$.

HANMER, S.K. 1979. The role of discrete heterogeneities and linear fabrics in the formation of crenulations. Jour. Struct. Geol., 1 (1):81-91.

HEILBRON, M.; VALERIANO, C.M.; ZIMBRES, E.; CHRISPIM SJ.; SIMÕES, L.S.M.; SOUZA, M.A.T. 1978. O contato basal do Grupo Canastra entre Itad de Minas e Carmo do Rio Claro, MG. In: SIMP. GEOL. DE MINAS GERAIS, 4, Belo Horizonte, 1978 Anais... Belo Horizonte, SBG/NMG. p. 179-198.

JOHNSON, A.M. \& ELLEN, S.D. 1974. A theory of concentric, kink and sinusoidal folding and of monoclinal flexuring of compressible elastic multilayers; I. Introduction. Tectonophysics, 21(2):301-339
MALTMAN, AJ. 1978. Serpentine textures in Anglesey. Geol. Soc. Am. Butt., 89 (7):972 -980.

MARINI, OJ; DARDENNE, M. A ; FUCK R.A ; DANNI, J.C.M. 1979. Mapa geológico da Faixa Brasília, escala 1:2.000.000. Brasília, UnB-Departamento de Geologia. (Publ. Int.).

POWELL, C. McA. 1979. A morphological classification of rock cleavage. Tectonophysics, 58 (1):21-34.

RAMSAY, J.G. 1967. Folding and fracturing of rocks. New York, McGraw-Hill. 568 p.

RAMSAY, J.G. 1980. Shear zone geometry: a review. Jour. Struct. $\mathrm{G} \ll ? 0 / ., 2(1 / 2): 83-99$.

RATTEY, P.R. \& SANDERSON, D J. 1982. Patterns of foldingwithin nappes and thrust belts: examples from the Variscan of Southv est England. Tectonophysics, 88 (2):247-267.

RIDLEY, J. 1986. Parallel stretching lineation and fold axis oblique to a shear displacement direction - a model and observations. Jour. Struct. Geol., 8 (6):647-653.

SANDERSON, DJ. 1979. The transition from upright to recumbent folding in the Variscan Fold Belt of Southwest England: a model based on the kinematics of simple shear. Jour. Struct. Geol., 1(3):171-180

SANDERSON, DJ. 1982. Models of strain variation in nappes and thrust sheets: a review. Tectonophysics, 88 (1/2):201-233.

SIMÕES, L.S.A. \& FUCK, R.A. 1984." Estratigrafia, deformação e metamorfismo do Grupo Araxá na região de Mossâmedes, Goiás In: CONGR. BRÁS. GEOL., 33, Rio de Janeiro, 1984. Anais.. Rio de Janeiro, SBG. v.7, p.3181-3195.

STRIEDER, A J. 1989. Geologia, petrologia e tectônica dos corpos de serpentinito de Abadiânia (GO). Brasília. 208p. (Dissertação de Mestrado, IG/UnB). (Inédito)

STRIEDER, A J. \& NILSON, A.A. Melange ofiolítica nos metassédimentos Araxá e implicações tectônicas regionais. Rev. Bras. Geol. (Subm.).

TURNER, FJ. \& WEISS, L.E. 1963. Structural analyses of metamorphic tectonites. New York, McGraw-Hill. $536 \mathrm{p}$.

WILLIAMS, P.F. 1985. Multiply deformed terrains - problems of correlation. Jour. Struct. Geol., 7 (3/4):269-280.
MANUSCRITO A628 Recebido em 06 de novembro de 1989 Revisão do autor em 04 de maio de 1990 Revisão aceita em 10 de junho de 1990 